\title{
Single-Cell Correlates of a Representational Boundary in Rat Somatosensory Cortex
}

\author{
Peter W. Hickmott and Michael M. Merzenich \\ Keck Center for Integrative Neuroscience, University of California, San Francisco, San Francisco, California 94143
}

In primary somatosensory cortex (S1), the transition from one representation to the next is typically abrupt when assayed physiologically. However, the extent of anatomical projections to and within the cortex do not strictly respect these physiologically defined transitions. Physiological properties, such as synaptic strengths or intracortical inhibition, have been hypothesized to account for the functionally defined precision of these representational borders. Because these representational borders can be translocated across the cortex by manipulations or behaviors that change the activity patterns of inputs to the cortex, understanding the physiological mechanisms that delimit representations is also an important starting point for understanding cortical plasticity.

A novel in vivo and in vitro preparation has been developed to examine the cellular and synaptic mechanisms that underlie representational borders in the rat. In vivo, a short segment of the border between the forepaw-lower jaw representations in rat S1 was mapped using standard electrophysiological methods and was visibly marked using iontophoresis of pontamine sky blue dye. Slices were then obtained from this marked region and maintained in vitro. Intracellularly recorded responses to electrical stimulation of supragranular cortex were obtained from single neurons near the border in response to stimulation within the representational zone or across the border. Both excitatory and inhibitory responses were smaller when evoked by stimuli that activated projections that crossed borders, as compared with stimuli to projections that did not. These findings indicate that intracortical network properties are contributing to the expressions of representational discontinuities in the cortex.

Key words: somatosensory cortex; representational boundary; horizontal connections; whole-cell recording; cortical slices; forepaw; lower jaw
A distinguishing characteristic of representational maps in the cerebral cortex is the presence of discrete regions that respond to a particular stimulus source. For example, in the somatosensory system, discrete regions of primary somatosensory cortex (S1) respond to stimulation of restricted regions of the body surface (Merzenich et al., 1978; Kaas, 1983; Chapin and Lin, 1984). Between these representations are sharp representational "discontinuities" or "borders," regions of the cortex in which the responses of the cortical neurons change from one representation to the other over a short distance across the cortex.

The cellular and circuit processes that underlie these sharply defined borders are not clear. The gross organization of cutaneous somatosensory representations results primarily from the organization of the projections to the cortex (Landry and Deschenes, 1981; Jensen and Killackey, 1987a; Rausell and Jones, 1995; Catalano et al., 1996). However, the projection patterns of both thalamocortical (Landry and Deschenes, 1981; Jensen and Killackey, 1987a; Rausell and Jones, 1995) and intracortical (Chapin et al., 1987; Fabri and Burton, 1991; Weiss and Keller, 1994; Hoeflinger et al., 1995) projections also overlap substantially in S1 and do not strictly respect representational borders. Thus, the underlying anatomy is not sufficient to explain the sharpness of the transition from one response region to another at

Received June 4, 1997; revised Feb. 26, 1998; accepted March 23, 1998.

This work was supported by National Institutes of Health Grants NS10414 and NS09859. We thank Drs. E. Ahissar, D. V. Buonomano, and P. A. Steen for helpful comments on various versions of this manuscript.

Correspondence should be addressed to Peter W. Hickmott, Keck Center for Integrative Neuroscience, University of California, San Francisco, P.O. Box 0732, San Francisco, CA 94143.

Copyright (C) 1998 Society for Neuroscience $\quad 0270-6474 / 98 / 184403-14 \$ 05.00 / 0$ a representational border. Some physiological mechanism or mechanisms must be invoked to explain their precision.

Much of the information about representational borders has been derived from studies concerning plasticity of cortical representations. Representational maps in the adult cerebral cortex can reorganize as a result of changes in the activity patterns of their inputs or because of behavioral training (Wang et al., 1995) (for review, see Merzenich et al., 1990; Kaas, 1991; Merzenich and Jenkins, 1993; Weinberger, 1995; Buonomano and Merzenich, 1998).

Although the cellular and simple-circuit mechanisms underlying reorganization of sensory cortex are incompletely understood, it is clear that at least part of the changes observed result from plasticity in the cortex itself (Kaas, 1991; Buonomano and Merzenich, 1998). Both the sprouting of new connections (DarianSmith and Gilbert, 1994) and the strengthening or weakening of existing excitatory or inhibitory synapses, which lead to "unmasking" of previously existing subthreshold connections, have been implicated in these reorganizations (Calford and Tweedale, 1988, 1991a,b; Donoghue et al., 1990; Nudo et al., 1990; Turnbull and Rasmussen, 1990; Byrne and Calford, 1991; Chino et al., 1992; Pettet and Gilbert, 1992; Recanzone et al., 1992a; Nicolelis et al., 1993).

The connections that are involved in representational plasticity in cortex are unclear. For example, in visual cortex, plasticity induced by binocular retinal lesions appears to be mediated by intrinsic horizontal connections in V1 (Darian-Smith and Gilbert, 1994, 1995; Das and Gilbert, 1995). In rat sensorimotor cortex, evidence suggests that plasticity is related to changes in both thalamocortical (Jensen and Killackey, 1987b; Armstrong-James 
et al., 1994; Rausell and Jones, 1995) and intracortical (Huntley and Jones, 1991; Armstrong-James et al., 1994; Weiss and Keller, 1994; Huntley, 1997) projections. Considering that both intracortical (Lee et al., 1991; Hirsch and Gilbert, 1993; Hess and Donoghue, 1994; Hess et al., 1996) and thalamocortical (Lee and Ebner, 1992; Kirkwood et al., 1993; Crair and Malenka, 1995) connections can exhibit synaptic plasticity, either or both would be reasonable candidates for rapid changes in representations. Recent data from rat S1 suggest that rapid plasticity depends on changes in the strengths of intracortical connections (ArmstrongJames et al., 1994).

In this paper, a combined in vivo and in vitro preparation is described in which the effects of a representational border on excitatory postsynaptic potentials (EPSPs) and inhibitory postsynaptic potentials (IPSPs) evoked in single cortical neurons by stimulation of supragranular horizontal connections were characterized. The data provide insights into possible mechanisms that allow the cortex to restrict excitation across borders between functionally defined, cortical regions. The ultimate goal is to determine how basic cellular phenomena account for the representational changes recorded in the cortex after peripheral input manipulations and in learning. Some of these data have been previously presented in abstract form (Hickmott and Merzenich, 1996).

\section{MATERIALS AND METHODS}

In vivo recording and production of marked slices. Using standard in vivo extracellular recording methods (Recanzone et al., 1992b; Xerri et al., 1994), a short section of the border between the forepaw-lower jaw representations was mapped in rat S1. Adult Sprague Dawley rats (280$350 \mathrm{gm})$ were anesthetized to an areflexic level with pentobarbital (50 $\mathrm{mg} / \mathrm{kg}$ of body weight, i.p.) and mounted in a stereotaxic frame. Supplemental doses of anesthetic were administered as needed. Atropine (0.054 $\mathrm{mg}$ ) was injected intraperitoneally to reduce respiratory secretion. Lidocaine $(2 \%)$ was injected subcutaneously around wound margins and at pressure points. Rectal temperature was monitored and maintained at $\sim 38^{\circ} \mathrm{C}$ with a heating pad. All surgical procedures were approved by the University of California San Francisco Committee on Animal Research.

After reflecting the skin and temporalis muscle, S1 was exposed via a wide craniotomy approximately centered on bregma, the dura was removed, and the cortex was covered with silicone oil. A computer image of the brain surface was recorded using a CCD camera and NIH Image software. Carbon-fiber electrodes (10 $\mu \mathrm{m}$ fiber diameter) designed to generate minimum damage were used for response mapping. The forepaw or lower jaw was stimulated with a fine glass probe to elicit multiunit cutaneous responses in S1. Responses were amplified $500 \times$ or $1000 \times$ (DAM-50 amplifier, W PI Instruments, or custom-built amplifier), filtered between $300 \mathrm{~Hz}$ and $10 \mathrm{kHz}$ (Krone-Hite Inc.), and fed into an oscilloscope and audio monitor. Responsiveness to forepaw and lower jaw stimulation was determined subjectively by listening to the audio monitor output. Penetrations were introduced into the forepaw zone, 1-2 mm rostral to bregma; subsequent penetrations were introduced more laterally until regions that responded to tactile stimulation of the lower jaw were encountered. Recordings were all at an approximate depth of $700-800 \mu \mathrm{m}$. The location of penetrations was recorded on the computer image of the cortex by using surface vasculature landmarks. Penetrations spaced $<50 \mu \mathrm{m}$ apart were then made to locate the border more exactly. Typically, three of these rows of penetrations were made and arranged perpendicular to the forepaw and lower jaw border, which is normally oriented roughly parallel to the midline. Rows were separated by $400-$ $500 \mu \mathrm{m}$ (see Fig. 1A). Three or four locations on the forepaw and lower jaw border were then marked by iontophoresis of Chicago sky blue (Sigma, St. Louis, MO) (2\% in $0.5 \mathrm{M} \mathrm{Na}$ acetate; $150-200 \mu \mathrm{m}$ below the surface for $6-8 \mathrm{~min}$, using $<0.5 \mu \mathrm{A}$ of ejection current; see Fig. $1 A$ ). Dye marks typically had initial diameters of $\sim 200 \mu \mathrm{m}$, but became smaller over time, reaching a final diameter of $10-50 \mu \mathrm{m}$ after $1-2 \mathrm{hr}$ in vitro.

After marking, the animal was decapitated, the brain was rapidly removed, and $400-\mu \mathrm{m}$-thick coronal slices were cut on a vibratome from the marked region of cortex. Slices with a dye mark locating the border that was defined previously were selected for use in vitro (see Fig. $2 A$ ).
The supragranular layers of the cortex were then isolated with a cut parallel to the cortical surface around layer $4(500-700 \mu \mathrm{m}$ from the cortical surface). These slices were maintained in standard mammalian bicarbonate buffer (in mM: $\mathrm{NaCl}, 119 ; \mathrm{KCl}, 2.5 ; \mathrm{NaH}_{2} \mathrm{PO}_{4}, 1.25 ; \mathrm{MgSO}_{4}$, 1.3; $\mathrm{CaCl}_{2}, 2.5 ; \mathrm{NaHCO}_{3}, 26.2$; and glucose, 11; saturated with $95 \% \mathrm{O}_{2}$ and $5 \% \mathrm{CO}_{2}$ ) for intracellular recording. Note that these and all subsequent chemicals were obtained from Sigma, unless otherwise stated. Slices were checked for viability and stability by recording maximal extracellular field potentials in layer 3 in response to electrical stimulation at or above layer $4(0.05 \mathrm{~Hz}$; see Fig. $2 B)$. Field potentials so obtained closely resembled those evoked in visual cortex by layer 4 stimulation (Kirkwood and Bear, 1994), consisting of a small rapid negativity followed by a main negativity at a latency of $\sim 5 \mathrm{msec}$ (see Fig. $2 B$, asterisk). Note that the small, slow negative potential evident after the main negative potential in the example in Figure $2 B$ was observed in the majority of cases; this slow negativity resulted from the relatively high-intensity stimuli presented close to the recording site and did not reflect any unhealthiness of the slice. Electrodes for field recording were glass of $\sim 1.5-2.5 \mu \mathrm{m}$ tip diameter, filled with $1 \mathrm{~N} \mathrm{NaCl} \mathrm{(1-4} \mathrm{M} \Omega$ resistance). Only slices in which stable fields with a main negativity (see Fig. $2 B$, asterisk) of $>0.6 \mathrm{mV}$ were used.

Intracellular recording. Neurons for recording were obtained using blind whole-cell recording (Blanton et al., 1989) from a region near the mark $(\sim 100-200 \mu \mathrm{m})$ in cortical layer $2 / 3$. Patch electrodes were pulled on a Flaming-Brown puller to a tip diameter of $1.5-2.5 \mu \mathrm{m}$ and filled with (in mM): Cs gluconate (Aldrich, Milwaukee, WI), 128; CsCl, 7; EGTA, 1; HEPES, 10; QX-314, 10; Mg ATP, 2; Na GTP, 0.2; and biocytin $0.3-0.5 \%, \mathrm{pH} 7.0-7.4$. Such electrodes had tip resistances of 3-8 $\mathrm{M} \Omega$. QX-314 (Research Biochemicals, Natick, MA) was included to block action potentials so that the amplitude of large postsynaptic potentials (PSPs) could be quantified. Only neurons with initial resting potentials of less than $-60 \mathrm{mV}$ and stable input resistances of $>50 \mathrm{M} \Omega$ were used. For recording PSPs, positive or negative current was injected to maintain the membrane potential at -50 to $-55 \mathrm{mV}$.

Recorded signals were amplified using an Axoclamp 2B amplifier (Axon Instruments, Foster City, CA), digitized at $10 \mathrm{kHz}$, and saved to the hard disk of a Gateway 486 computer using Experimenter's Workbench (DataWave Inc.) data acquisition system. PSPs were recorded in these neurons in current-clamp mode by stimulating layer $2 / 3$ at the same distance from the cortical surface as the cell. The stimulating electrode was a bipolar, parylene-coated $1 \mathrm{M} \Omega$ tungsten electrode with a tip separation of $\sim 100-150 \mu \mathrm{m}$ (FHC Inc.). Stimuli were divided into two categories based on the horizontal distance of the stimulation sites from the impaled neuron: the first category consisted of stimuli within $300 \mu \mathrm{m}$ of the neuron and is referred to as close stimulation; the second consisted of stimuli between 450 and $800 \mu \mathrm{m}$ and is referred to as distant stimulation. Usually a given neuron was only stimulated in one of these categories. To examine possible effects at the border on connections within cortical layer $2 / 3$, brief electrical stimuli (100 $\mu$ sec duration, 0.1 $\mathrm{Hz}$ ) were presented in layer $2 / 3$ at one of two locations with respect to the impaled neuron. The first location was across the border from the patched neuron, either at a close or distant site, and the second location was at the same horizontal distance from the neuron as the first site, but on the other side of the neuron. Thus, in the second case there was no border interposed between recording and stimulating electrodes. Throughout this paper, the first case, cross border stimulation, will be referred to as "CB stimulation" and the second case, noncross border stimulation, will be referred to as "NCB stimulation". Both sites were at the same distance from the cortical surface as the impaled neuron. This recording and stimulating configuration is schematized in Figure $2 \mathrm{~A}$, left, in which the locations of $\mathrm{CB}$ (black square) and NCB (gray square) stimulation are shown with respect to the border (open circle) and recording site (inverted triangle). Thus, one stimulus site was in the forepaw representation and one in the lower jaw representation, as determined by the in vivo mapping. To minimize variability, the same stimulating electrode at the same polarity was used for both stimuli and was approximately positioned with the aid of a microscope eyepiece graticle. The electrode position was then more precisely adjusted to equalize the time from stimulus to PSP initiation between CB and NCB stimulation. PSPs were evoked at both of these sites starting below the minimal intensity necessary to evoke a PSP and gradually increased to a supramaximal intensity, thus generating a complete input-output (I-O) curve for each neuron. The same stimulus intensities were used at both sites of stimulation except when lower and higher stimuli were necessary to define the minimal and maximal responses. Because sodium- 
dependent spikes were blocked with intracellular QX-314, it was possible to record pure PSPs even at high stimulus intensities in most cells. However, in some cells large voltage-activated potentials were evoked by larger PSPs; these cells were not used for PSP analysis, although they were sometimes used for analysis of pure IPSPs (see below). PSPs were evoked around the reversal potential for IPSPs, typically at -50 to -55 $\mathrm{mV}$. The average of three to five individual PSPs was used for quantification at each stimulus intensity (see Fig. 3).

Control data. To control for possible nonspecific effects of the mapping, marking, and slicing procedures, the forepaw-lower jaw region was mapped in vivo as above, but dye marks were placed $300-500 \mu \mathrm{m}$ medial to the border. These marks were specifically placed near the center of the forepaw representation at a distance from major representational borders. Control data were obtained from neurons close to these dye marks in a manner identical to that detailed above for neurons close to the marked border. The resulting PSPs were also analyzed identically, as detailed below. Thus, data were obtained from these neurons as detailed above, but no representational borders were close to the neurons, only a dye mark. As shown in Figure $2 A$, right, the stimulating electrodes in these control preparations were placed in two locations: either at a site in layer $2 / 3$ in which the dye mark (open circle) was between the recording (inverted triangle) and stimulating electrodes [cross-mark (CM) stimulation, black square], or at an equidistant site on the opposite side of the neuron, in which there was no dye mark interposed [ non-cross-mark (NCM) stimulation, gray square]. Thus, NCM stimulation was equivalent to NCB stimulation, whereas CM stimulation was analogous to $\mathrm{CB}$ stimulation. However, in the control slices, no border intervened between the CM stimulation site and the recording site, as opposed to the $\mathrm{CB}$ case, in which the dye mark and the border coincided. Control data were only obtained using close stimulation (i.e., $<300 \mu \mathrm{m}$ from the neuron).

Analysis of PSPs. For each stimulus intensity, two PSP characteristics were determined: the peak amplitude of the PSP and the time required for the potential to fall from peak amplitude to one-half the peak amplitude $\left(t_{1 / 2}\right)$. This measure of fall time was chosen as a method of quantifying later components of the PSP. From these measures, three parameters that summarize the data across stimulus intensities were defined (see Fig. 3B). (1) The maximal peak amplitude $\left(\mathrm{pk}_{\max }\right)$ and (2) the steepness of the input-output function (Salin and Prince, 1996) were defined. Because the I-O plots were asymptotic, they were generally well fit by a single exponential function (see Fig. $3 B$, left ). The steepness of the $\mathrm{I}-\mathrm{O}$ function was thus measured by fitting an exponential to the data and calculating the value of $\tau(\mathrm{I}-\mathrm{O} \tau)$. Smaller $\mathrm{I}-\mathrm{O} \tau$ values reflect steeper slopes of the submaximal portion of the I-O curve. Note that for one neuron in the analysis of IPSPs, the $\tau$ values were not used in the analysis, because the $R^{2}$ value for both CB and NCB stimulation was $<0.5$ (see Fig. $6 B$ ). (3) The ratio of the mean of the $t_{1 / 2}$ values from the PSPs elicited by the higher $50 \%$ of the stimuli $\left(\mathrm{t}_{1 / 2}\right.$, high) (see Fig. $3 B$, right plot, squares) divided by the mean $\mathrm{t}_{1 / 2}$ values from PSPs elicited by the lower $50 \%$ of the stimuli $\left(\mathrm{t}_{1 / 2}\right.$, low) (see Fig. $3 B$, right plot, circles) was also defined. This ratio (referred to as $h / 1$ ratio) was used as a measure of the contribution of later responses to the compound PSP (see Figs. 3, 4).

Two additional parameters were also measured: the threshold stimulus intensity required to evoke a minimal PSP and the latency of the PSP. Because the latency decreased slightly at higher stimulus intensities, the latency was measured for relatively small PSPs ( $\sim 5 \mathrm{mV}$ amplitude).

To determine whether there was an effect of the representational border, parameters were compared for $\mathrm{CB}$ and $\mathrm{NCB}$ (or CM and NCM in control slices) stimulation using paired, two-tailed Student's $t$ tests; $p<0.05$ was taken to be significant.

Reversal potentials were determined in voltage-clamp mode by evoking postsynaptic currents (PSCs) at various holding potentials (typically from -80 to $+20 \mathrm{mV})$. All PSCs were evoked by close stimulation $(<300$ $\mu \mathrm{m})$. The reversal potential was determined at three regions of PSCs: (1) at the peak of the PSC evoked by minimal stimulation, which estimated the contributions of EPSCs and IPSCs to monosynaptic responses; (2) at the peak of a PSC evoked at maximal stimulation, which estimated the contributions of higher-threshold monosynaptic and rapid disynaptic responses; and (3) at a point $20 \mathrm{msec}$ after the peak of the PSC evoked at maximal stimulation, which was approximately at the peak of the IPSC and estimated the contribution of longer latency events.

Analysis of IPSPS. To isolate monosynaptic IPSPs, a combination of 10-15 $\mu \mathrm{M}$ 6,7-dinitroquinoxaline-2,3-dione (DNQX; Research Biochemicals) or 6-cyano-7-nitroquinoxaline-2,3-dione (CNQX; Research Biochemicals) and $100 \mu \mathrm{M}$ DL-2-amino-5-phosphonopentanoic acid (APV) was bath-applied via the perfusion system for $>10 \mathrm{~min}$. PSPs at several stimulus intensities from minimal to maximal were obtained for both $\mathrm{CB}$ and NCB sites. The peak amplitude and the $t_{1 / 2}$ were determined for the IPSP at each intensity, and the maximal peak amplitudes ( $\left.\operatorname{ipk}_{\max }\right)$, I-O $\tau(\mathrm{I}-\mathrm{O} \mathrm{i} \tau)$ and the average and maximal $\mathrm{t}_{1 / 2}\left(\mathrm{it}_{1 / 2}\right.$ avg and $\mathrm{it}_{1 / 2} \max$, respectively) were determined for $\mathrm{CB}$ and $\mathrm{NCB}$ stimulation. Typically, IPSPs were recorded at -40 to $-45 \mathrm{mV}$. Values were compared using paired $t$ tests, as for the analysis of PSPs. Reversal potentials were also determined for the peak of pure IPSCs in a manner similar to that described above. Note that isolated IPSPs could only be recorded reliably with close stimulation.

Cytochrome oxidase histochemistry. After mapping and marking of the forepaw-lower jaw border, as detailed above, a small $(\sim 2 \mathrm{~mm}$ in the rostral-caudal dimension) piece of cortex around the marked border was removed and fixed in $4 \%$ paraformaldehyde overnight. The tissue was then rinsed in $0.1 \mathrm{M}$ PBS and sectioned in the coronal plane at 50 or 100 $\mu \mathrm{m}$ on a vibratome. These sections were then reacted for cytochrome oxidase (Wong-Riley and Welt, 1980) in a solution consisting of 0.5 $\mathrm{mg} / \mathrm{ml}$ diaminobenzidine, $0.3 \mathrm{mg} / \mathrm{ml}$ cytochrome $\mathrm{C}$ (type III), and 0.2 $\mathrm{mg} / \mathrm{ml}$ catalase in $0.1 \mathrm{M}$ PBS. The reaction was allowed to proceed at $37^{\circ} \mathrm{C}$ until staining was clearly visible $(\sim 4 \mathrm{hr})$. Sections were then rinsed in PBS, mounted on slides in $90 \%$ glycerol and $10 \%$ PBS, and examined at low power.

Throughout this paper, values are expressed as mean \pm SEM, unless otherwise indicated.

\section{RESULTS}

In this study, the border between the forepaw and lower jaw representations was mapped in vivo using standard extracellular mapping techniques, and the border then was visibly marked by iontophoresis of Chicago sky blue dye. Coronal slices from the marked region were maintained in vitro, and the synaptic responses of single neurons to stimuli of infragranular cortex were compared for stimuli that were delivered across the border versus equidistant stimuli that were not. Differences in both excitation and inhibition evoked by $\mathrm{CB}$ versus $\mathrm{NCB}$ stimulation were discovered.

\section{Mapping the forepaw-lower jaw border in vivo}

Initially, a short segment $(\sim 1.5 \mathrm{~mm})$ of the border between the forepaw and lower jaw representations was mapped using standard extracellular techniques in vivo. As observed previously in the rat (Chapin and Lin, 1984; Waters et al., 1995), extracellular response mapping revealed a relatively sharp discontinuity between the forepaw and lower jaw representations (Fig. 1A). However, in a number of animals, single penetrations that exhibited responses to stimulation of both the forepaw and lower jaw (Fig. $1 A$, open circles), typically unequally and relatively weakly, were obtained. These dual response penetrations were frequently associated with a lighter state of anesthesia. The forepaw-lower jaw responsive penetrations could have resulted from the use of multiunit responses to map the border, and/or from the activation of noncutaneous deep inputs from the joints or muscles by our relatively vigorous stimulation. Also, considering that penetrations near the border were in perigranular cortex (Fig. $1 B$ ) and such cortex contains neurons with large receptive fields (Chapin and Lin, 1984), it is not surprising that such dual-response penetrations were obtained. Furthermore, cutaneous receptive fields are known to expand in unanesthetized animals (Chapin and Lin, 1984). Thus, the degree of response overlap in the map of S1 should increase with lighter anesthesia. When such a penetration was obtained, the border between forepaw and lower jaw representations was drawn through that point. In cases in which there were no dual-response penetrations, the border was drawn halfway between the adjacent penetrations, separated by $\sim 50 \mu \mathrm{m}$, in which exclusive forepaw and lower jaw responses were recorded.

Dye marks were placed along the border as indicated in Figure 
A

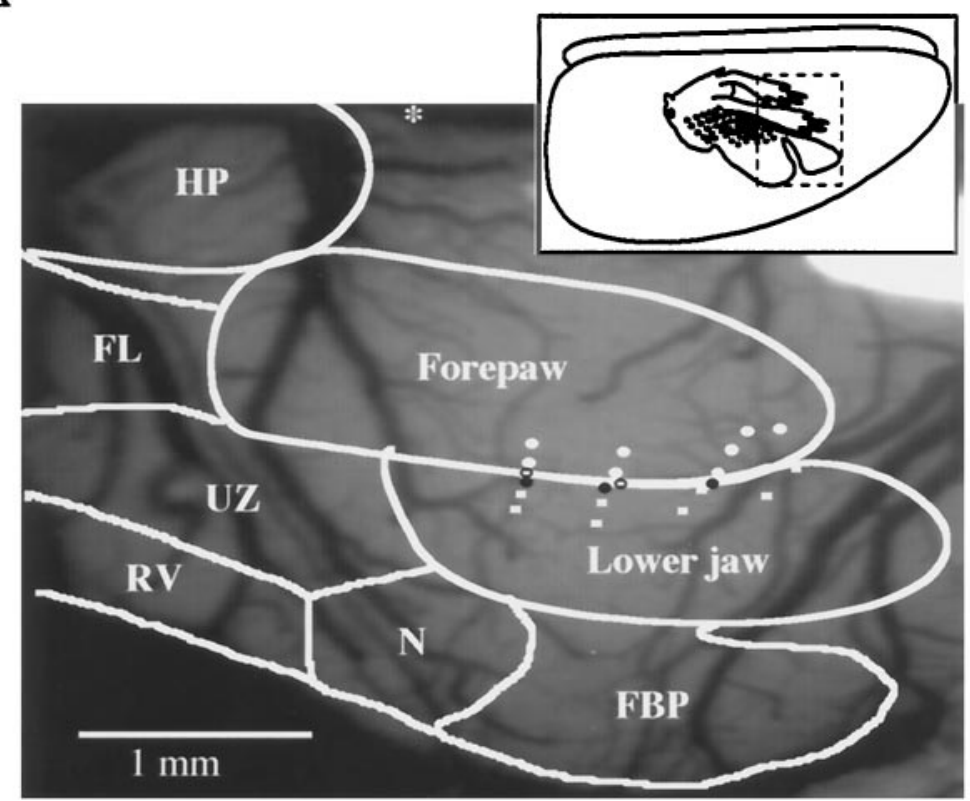

B

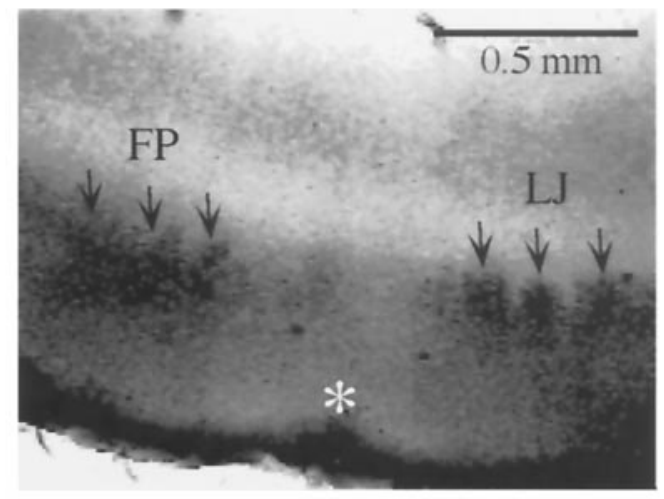

Figure 1. A, Example of mapping the forepaw-lower jaw border. Inset shows a schematic of a lateral view of the rat cortex, indicating the approximate location of the "ratunculus"; dashed box indicates the approximate location of the craniotomy and the body surface map illustrated in the main figure. An outline of the rat S1 map is superimposed over the surface of the cortex (Chapin and Lin, 1984). White circles represent penetrations responding to forepaw stimulation, white squares represent lower jaw responsive penetrations, and open circles reflect penetrations responding to both. Black circles represent the dye marks that defined the border between representations. The asterisk is placed at bregma, rostral is to the right, lateral is toward the bottom. $F B P$, Frontal buccal pads; $N$, nose; $R V$, rostral vibrissae; $U Z$, unresponsive zone; $F L$, forelimb; $H P$, hindpaw. $B$, Cytochrome oxidase staining from a marked slice (100 $\mu \mathrm{m}$ thick). The location of the mark is indicated by the asterisk, and the arrows point to individual barrels in layer 4 in the forepaw $(F P)$ and lower jaw $(L J)$ representations. Medial is to the left and the surface of the cortex is at the bottom.

$1 A$ (black circles) using low-current iontophoresis. Considering that intracortical microstimulation has been shown to change the size of cortical representations in vivo (Nudo et al., 1990; Recanzone et al., 1992a), albeit with higher intensities and longer durations, we remapped the same border after marking $(n=5$, data not shown). There was no evidence of any effect of the iontophoresis on the location of the border. Furthermore, both bis-benzimide staining for nuclei $(n=3)$ and cresyl violet Nissl staining $(n=4)$ in sections from the marked region showed no evidence for any lesion or other discernible damage to neurons in the region of the mark (data not shown). Dye marks decreased in size over the course of the experiment, with a typical starting diameter of $\sim 200 \mu \mathrm{m}$ and a typical final diameter of $\sim 10-50 \mu \mathrm{m}$.

To relate the location of the physiologically defined border to the cytoarchitectural correlates of the forepaw and lower jaw representations, we examined sections from mapped and marked cortex that were then stained for cytochrome oxidase. This procedure allows the differentiation of granular from perigranular and agranular regions of S1 cortex (Chapin and Lin, 1984; Fabri and Burton, 1991), and the cytochemically defined representations generally correspond to the physiologically defined (Waters et al., 1995, but see McCandlish et al., 1996). As shown in Figure $1 B$, the physiologically defined border (asterisk) falls in perigranular cortex between the forepaw granular region and the lower jaw granular region.

\section{In vitro recording}

Recordings were obtained from 36 neurons in marked slices, 25 of which were used for close stimulation $(<300 \mu \mathrm{m})$ and 11 of which were used for distant stimulation $(>450 \mu \mathrm{m})$, and from $12 \mathrm{neu}-$ rons from control slices. A schematic of the marked slice prepa- ration is shown in Figure $2 A$, left, whereas a schematic of a control slice is shown in Figure $2 A$, right. All neurons were recorded in superficial cortical layers (mean estimated distance from cortical surface, $248 \pm 8 \mu \mathrm{m}$ ). For the close stimulation category, the mean estimated distances of the stimuli from the neuron were $210 \pm 6 \mu \mathrm{m}$ for $\mathrm{CB}$ and $\mathrm{CM}$ stimulation and $213 \pm$ $7 \mu \mathrm{m}$ for NCB and NCM stimulation. For the distant stimulation category, the mean estimated distance was $621 \pm 25 \mu \mathrm{m}$ for $\mathrm{CB}$ and $626 \pm 26 \mu \mathrm{m}$ for NB stimulation. Kruskal-Wallis tests followed by planned Mann-Whitney $U$ tests revealed that the distances for close stimulation were not significantly different $(p>0.6)$, whereas those from distant stimulation were significantly different from both the marked and control distances $(p<$ $0.0001)$. The equivalence of the stimulation distances between $\mathrm{CB}$ and NCB stimulation was confirmed by examining the latency from stimulus artifact to PSP onset for each stimulation site; latencies were $2.63 \pm 0.1 \mathrm{msec}$ for $\mathrm{CB}$ and $\mathrm{CM}$ and $2.58 \pm 0.1$ msec for NCB and NCM stimulation ( $p>0.4$; Mann-Whitney test). Note that the preceding latency data are presented pooled across both control and marked slices, because these values did not differ significantly between control and marked slices (MannWhitney tests; $p>0.5$ ). In marked slices, neurons ranged from 100-350 $\mu \mathrm{m}$ from the mark; for close stimulation, the mean was $140 \pm 5 \mu \mathrm{m}$ and for distant stimulation the mean was $179 \pm 23$ $\mu \mathrm{m}$. These values were significantly different $(p<0.05$; MannWhitney $U$ test). All cells were obtained randomly on either the medial (forepaw zone) or lateral (lower jaw zone) side of the mark. Nonparametric tests were used to compare these data because their frequency distributions were generally not normal (Fig. 2C). 
A

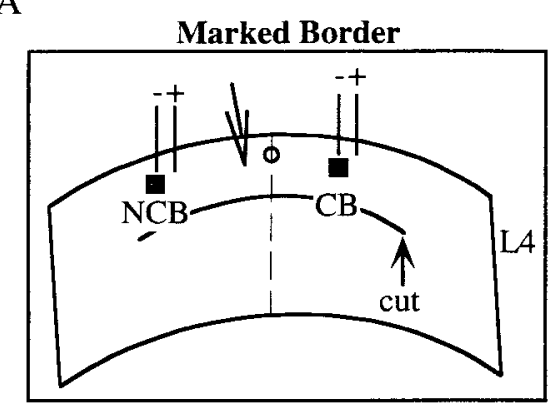

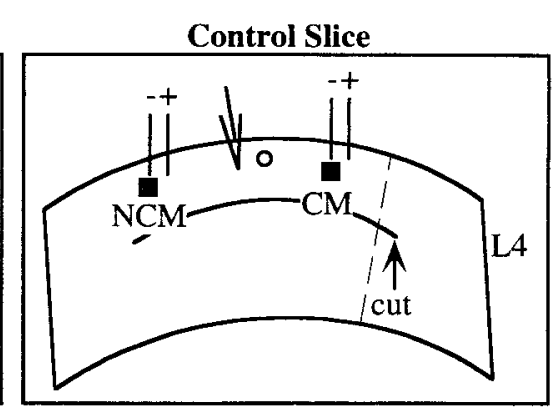

B

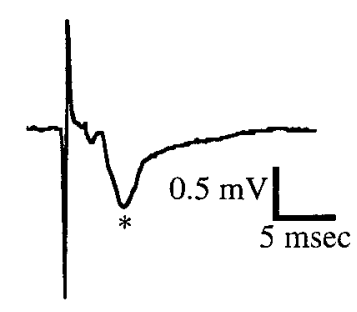

C
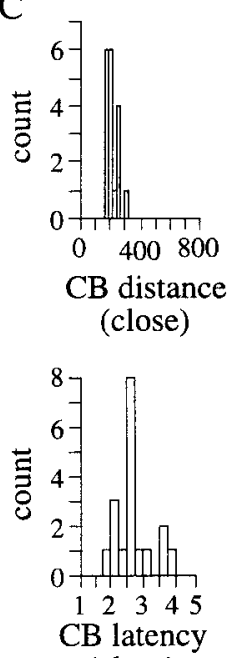

(close)

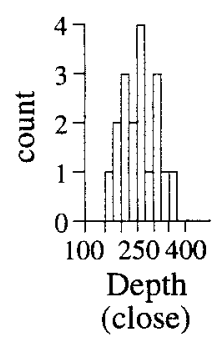

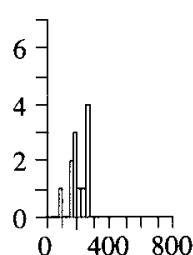

$\mathrm{CM}$ distance
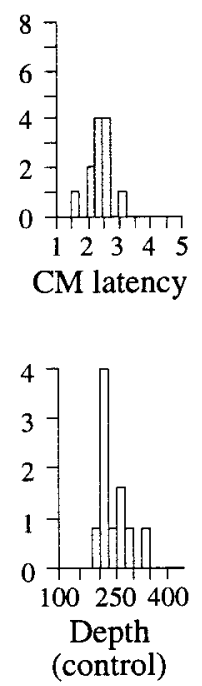

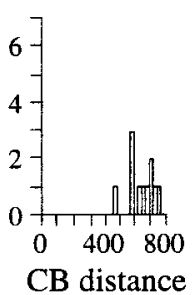

(distant)

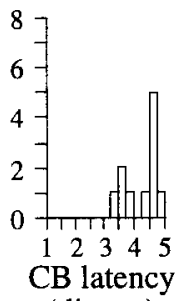

(distant)

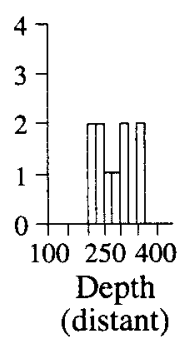

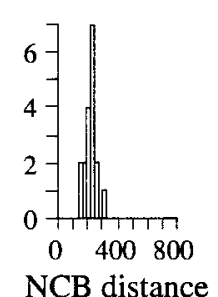
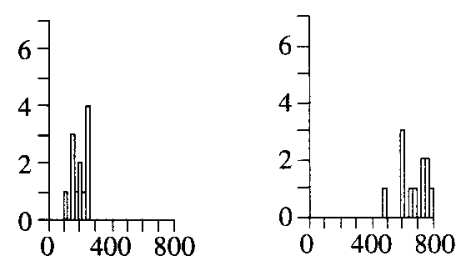

(close)

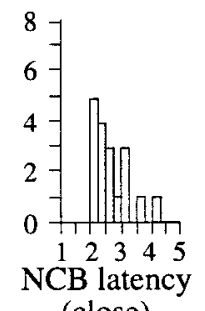

(close)

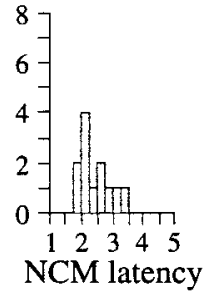

$\begin{array}{ccccc}1 & 2 & 3 & 4 & 5 \\ \text { NCM latency }\end{array}$
NCB distance

(distant)

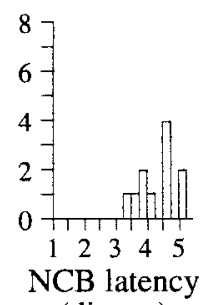

(distant)

Figure 2. The slice preparation: stimulating and recording parameters. $A$, Schematic representations of coronal slices taken from rat $\mathrm{S} 1 \mathrm{used}$ in these studies. In both schematics, the inverted triangle represents the recording electrode, the heavy line represents the cut placed in layer 4 to isolate supragranular layers, and the dotted line represents the location of the border between the forepaw and lower jaw representations. The parallel lines represent the stimulating electrodes, with the polarities of the two electrodes indicated. Note that the same polarity configuration was used between $\mathrm{CB}$ and NCB stimulation, so that the same electrode of the bipolar pair was at the stimulation site. Left panel, Schematic of a slice in which the border between the forepaw and lower jaw was marked before slicing. Black square, Cross-border $(C B)$ simulation site; gray square, noncross-border (NCB) stimulation site; open circle, dye mark, dotted line, border. Right panel, Schematic of a control slice in which the dye mark (open circle) was placed at a site in the forepaw representation of S1 away from the border (dotted line). Black square, Cross-mark (CM) stimulation site (note that no border is interposed between stimulating and recording); gray square, noncross mark (NCM) stimulation site. B, Example of a maximal amplitude field potential recorded from a slice in which the forepaw-lower jaw border was marked in vivo. The potential was recorded in cortical layer 3 in response to electrical stimulation $(90 \mu \mathrm{A})$ above cortical layer 4. This trace is the average of 20 individual potentials. The asterisk marks the main negativity (see Materials and Methods). $C$, Frequency distributions of estimated stimulation distances from neurons, latencies from stimulus to PSP onset, and estimated distances of neurons from the cortical surface (i.e., depth), for close stimulation, control slices, and distant stimulation. For distances and latencies, data from both cross and noncross stimulating cases are shown. These distributions clearly demonstrate that these data are generally poorly fit by a normal distribution, and thus nonparametric statistical tests were used to compare them.

The mean resting potential of sampled neurons (pooled for all neurons) was $-70 \pm 0.7 \mathrm{mV}$, and the mean input resistance was $114.8 \pm 3.5 \mathrm{M} \Omega$. Because of the presence of $\mathrm{Cs}^{+}$and QX-314 in the electrode filling solution, these initial values increased over the course of $10-15 \mathrm{~min}$, reaching mean values of $-42.4 \pm 1.4$ $\mathrm{mV}$ and $147.1 \pm 6.7 \mathrm{M} \Omega$, respectively. Only after these values were unchanging for $>2-3$ min were data collected from the neuron.

\section{Characteristics of PSPs and effects of the border-close stimulation category}

Figure $3 A$ shows examples of PSPs evoked with CB (left) and NCB (right) stimulation at various stimulus intensities. These PSPs are compound events, consisting of monosynaptic and polysynaptic contributions by both EPSPs and IPSPs. At low stimulus intensities, small and longer duration PSPs, which were 
A)

Cross-border (CB) stimulation

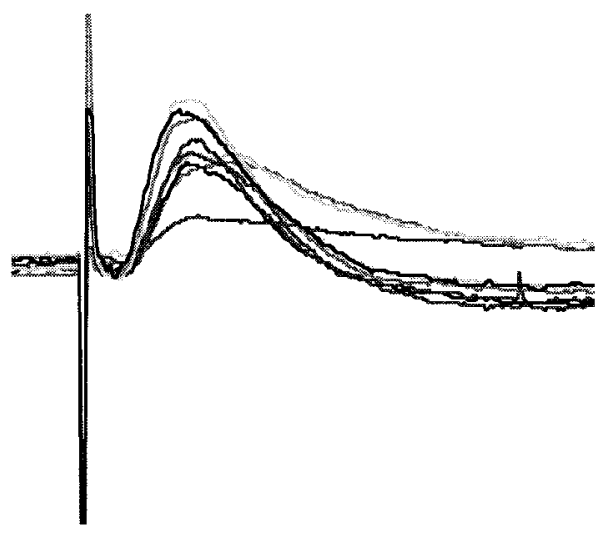

B)
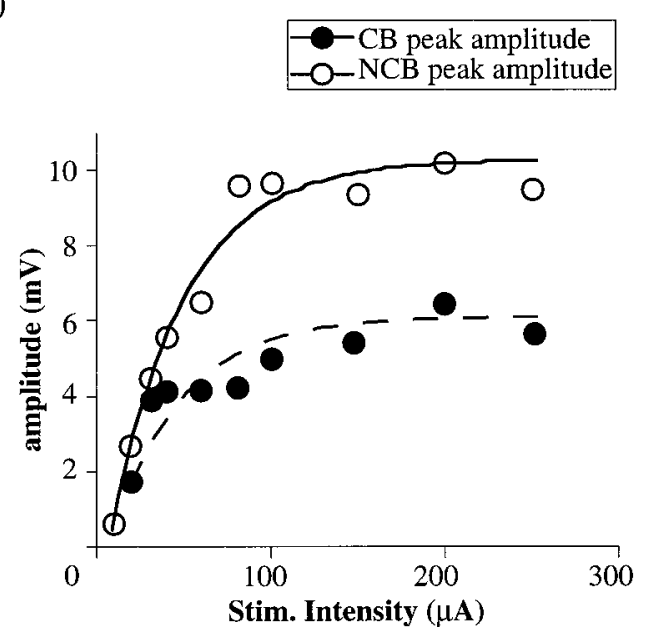
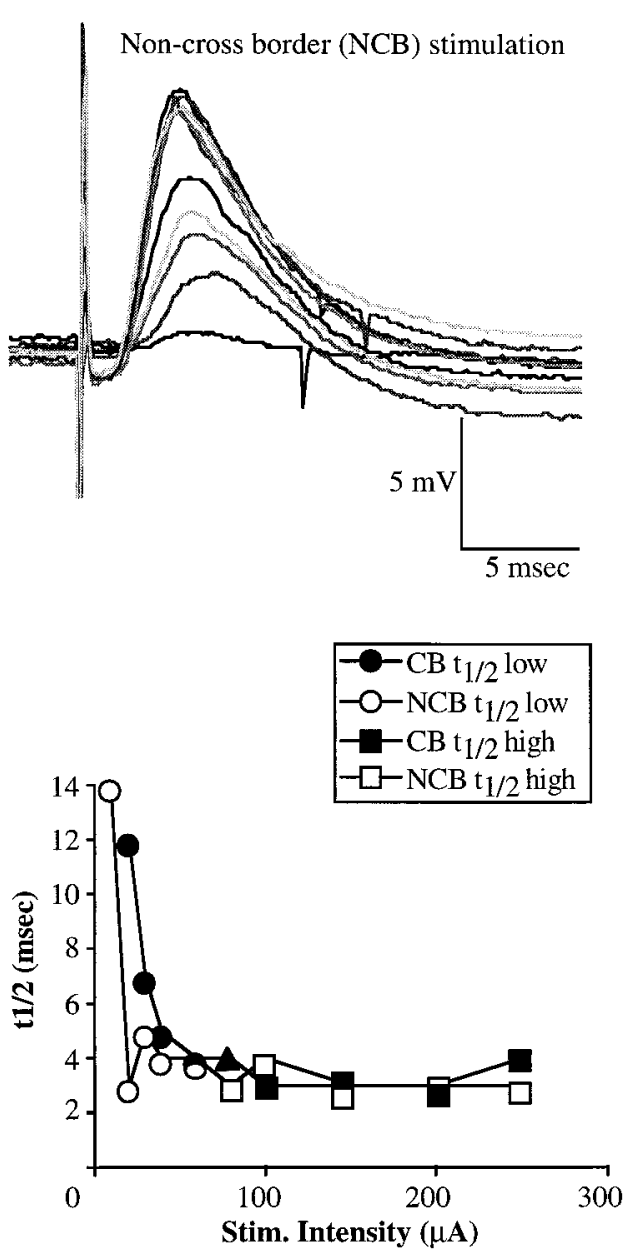

Figure 3. A, Examples of PSPs evoked by close stimulation $(\sim 240 \mu \mathrm{m}$ in this example) for cross-border $(C B$, left $)$ and non-cross-border (NCB, right) stimulation. Traces range from the minimal to maximal responses at each site, and each is the average of 3-5 individual responses. Corresponding shades of gray represent responses from corresponding stimulus intensities; four gray levels are used to differentiate intensities, and thus the grays repeat every fifth intensity. Membrane potential of this neuron was adjusted to $-55 \mathrm{mV}$. $B$, Quantification of the PSPs shown in $A$. Filled symbols indicate CB stimulation, whereas open symbols indicate NCB. The left plot shows the amplitude at the peak of each PSP in $A$. The lines represent the best exponential fit of the input-output curve; the solid line is fitted to the data from NCB stimulation, and the broken line is fitted to data from CB stimulation. The right plot shows the $50 \%$ decay time $\left(\mathrm{t}_{1 / 2}\right)$ for each PSP. In the right plot, $\mathrm{t}_{1 / 2}$ values from the lower $50 \%$ of stimuli (whose mean equals $\mathrm{t}_{1 / 2}$ low) are shown by circles, whereas the $t_{1 / 2}$ values from the upper $50 \%$ of stimuli (whose mean equal $t_{1 / 2}$ high) are shown by squares. Note that when there was an odd number of stimulus intensities, the data from the centermost point were not used in the calculation of the $\mathrm{h} / \mathrm{l}$ ratio (Fig. $2 \mathrm{~B}$, right, filled triangle).

depolarizing at approximately $-50 \mathrm{mV}$, were typically obtained; these were initially thought to be relatively pure monosynaptic EPSPs. However, in some cases (5 of 33) the response to the threshold stimulus was negative at approximately $-50 \mathrm{mV}$, indicating monosynaptic IPSPs (Fig. 4; see Fig. 6). At higher stimulus intensities, larger and more rapid depolarizing events were obtained, usually followed by a relatively long hyperpolarization. The peak amplitudes (left) and $\mathrm{t}_{1 / 2}$ values (right) of each of these PSPs are quantified across stimulus intensities for $\mathrm{CB}$ (filled circles) and NCB (open circles) in Figure $3 B$. For the amplitude (Fig. $3 B$, left), there was a progressive increase with increasing stimulus intensity until the amplitude plateaued. The lines in Figure $3 B$, left, represent the exponential fit to the I-O curve; values of $\tau$ for these fits were used as a measure of the steepness of the submaximal region of the curve. This increase in amplitude is apparently caused by activation of higher-threshold excitatory inputs to the neuron (Fig. 4).

There was also a rapid decrease in $t_{1 / 2}$ with increasing stimulus intensity that plateaued at a minimum (Fig. 3B, right). To quantify the effects of increasing stimulus intensity on the longer-latency component of the PSPs, the ratio of the mean $t_{1 / 2}$ resulting from higher-intensity stimuli (Fig. $3 B$, right, squares) to the mean $t_{1 / 2}$ resulting from lower-intensity stimuli (Fig. $3 B$, right plot, circles) was calculated. This ratio is termed the $\mathrm{h} / \mathrm{l}$ ratio (see Materials and Methods). Thus, a decrease in the $h / 1$ ratio could either reflect a smaller mean $t_{1 / 2}$ at high stimulus intensities or by a larger $t_{1 / 2}$ at low stimulus intensities, or both. This decrease was apparently caused by the activation of IPSPs, both monosynaptic and polysynaptic, at higher stimulus intensities (Fig. 4). The values of these PSP parameters are summarized in Table 1 and Figure 5.

To differentiate more precisely between excitation and inhibition, the reversal potentials of various parts of PSCs corresponding to the early and late components of the PSP, were determined. The mean reversal potential of PSCs evoked by minimal stimulation was $-21 \pm 4 \mathrm{mV}$ (Fig. $4 A$, circles; $n=7$ ), indicating that 
A)

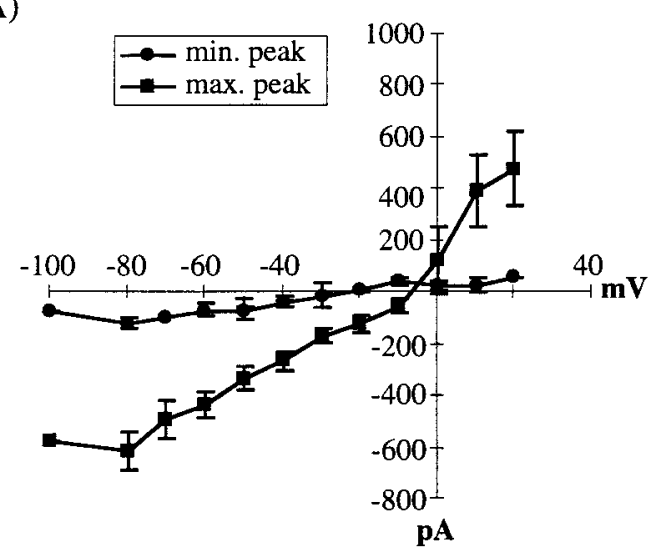

B)

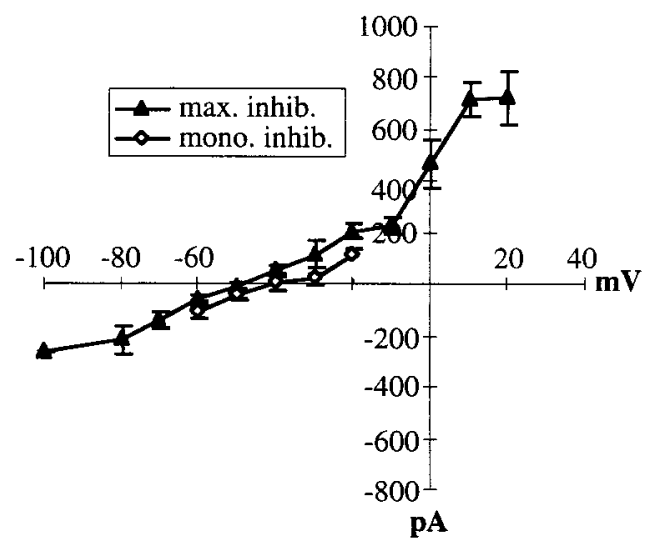

Figure 4. Mean current-voltage ( $I-V$ ) relations for PSCs evoked by close stimulation pooled for CB and NCB cases. Each curve represents the mean peak current obtained for the indicated PSC. $A, I-V$ curves reflecting primarily excitation. Circles are from the peak of the current evoked by minimal stimulation $(n=7)$. Squares are from the peak of the current evoked by maximal stimulation $(n=7) . B, I-V$ curves reflecting primarily inhibition. Triangles are from currents measured at $20 \mathrm{msec}$ after the peak of the maximal current $(n=10)$. Diamonds are from the peak of isolated IPSCs $(n=6)$.

Table 1. PSP parameters

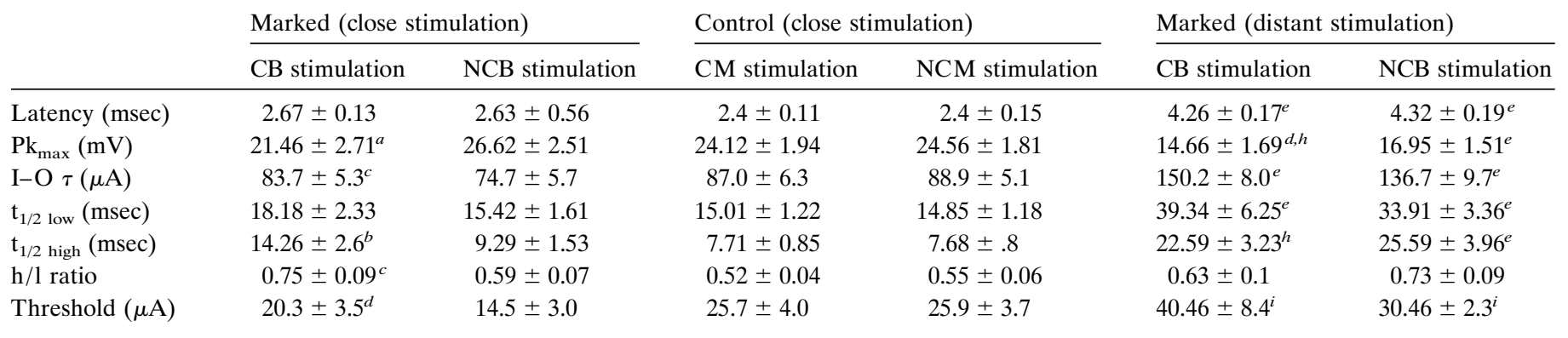

Close and distant refer to the distance between stimulation and recording site: close was $<300 \mu \mathrm{m}$ and distant was $>450 \mu \mathrm{m}$.

Parameters from CB and NCB or CM and NCM stimulation were compared using paired Student's $t$ tests for each category.

Parameters were compared across categories using a factorial ANOVA, followed by post hoc comparisons (Fisher's protected least-squares difference) between each of the individual categories.

${ }^{a}$ Significantly different from corresponding NCB stimulation, $p<0.0001$.

${ }^{b}$ Significantly different from corresponding NCB stimulation, $p<0.005$.

${ }^{c}$ Significantly different from corresponding NCB stimulation, $p<0.01$.

${ }^{d}$ Significantly different from corresponding NCB stimulation, $p<0.05$.

${ }^{e}$ Significantly different from marked close or control, $p<0.0001$.

${ }^{f}$ Significantly different from marked close or control, $p<0.005$.

${ }^{g}$ Significantly different from marked close or control, $p<0.01$.

${ }^{h}$ Significantly different from marked close or control, $p<0.05$.

${ }^{i}$ Significantly different from marked close, $p<0.005$.

even the threshold monosynaptic PSCs (and thus PSPs) were a mixture of EPSCs and IPSCs. To examine the contributions of EPSCs and IPSCs to PSCs evoked by maximal stimulation, the reversal potentials at the peak of the PSC (Fig. 4A, squares) and at a point $20 \mathrm{msec}$ after the peak (Fig. $4 B$, triangles) were determined. The mean reversal potential of the peak of the large PSCs was $-4 \pm 4 \mathrm{mV}(n=7)$, indicating that the peak of these larger PSCs primarily reflected the recruitment of monosynaptic and polysynaptic EPSCs. At $20 \mathrm{msec}$ after the peak of the maximal PSC, the reversal potential was $-50 \pm 2 \mathrm{mV}(n=10$, Fig. $4 B$, triangles), indicating strong activation of IPSCs, which caused the sharp decrease in the fall time with stronger stimulation. This value did not differ significantly from the value obtained for pure, monosynaptic IPSCs obtained in the presence of DNQX and APV ( $-47 \pm 6 \mathrm{mV}, n=6$; Fig. $4 B$, diamonds). Generally, the current-voltage relations of EPSCs were approximately linear below $0 \mathrm{mV}$, an observation that differs from that observed by other investigators (Sutor and Hablitz, 1989b; Hirsch and Gilbert, 1991). It is likely that the inclusion of QX-314, cesium, or both in the filling solution blocked voltage-dependent conductances that have been suggested to underlie this voltage dependence (Sutor and Hablitz, 1989b; Hirsch and Gilbert, 1991).

The mean values of several PSP parameters for both CB and NCB stimulation (or CM and NCM stimulation for control slices) are presented in Table 1 . In Figure $5 A$, the mean differences between responses to $\mathrm{NCB}$ and $\mathrm{CB}$ stimulation in marked slices (hatched bars) and between responses to NCM and CM stimulation in control slices (solid bars) are presented and compared (unpaired $t$ tests) for some of these parameters. In Figure $5 B$, the individual differences ( $\mathrm{NCB}-\mathrm{CB}$, or $\mathrm{NCM}-\mathrm{CM}$ for control) used to generate the means in Figure $5 A$ for each neuron are presented. Note that the data in Figure 5 is from PSPs evoked by 
A) Mean non-cross border (NCB) minus cross border (CB) differences

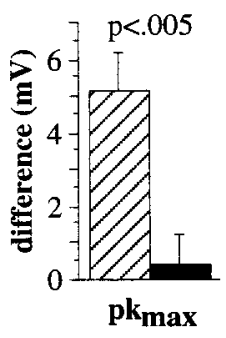

B) Individual differences (NCB-CB)

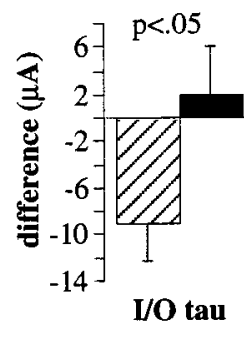

O tau

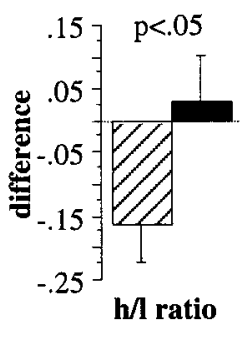

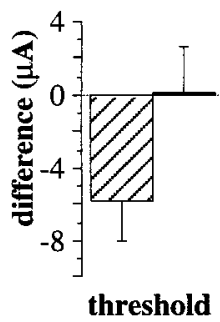

$\square$ marked $(\mathrm{n}=18)$
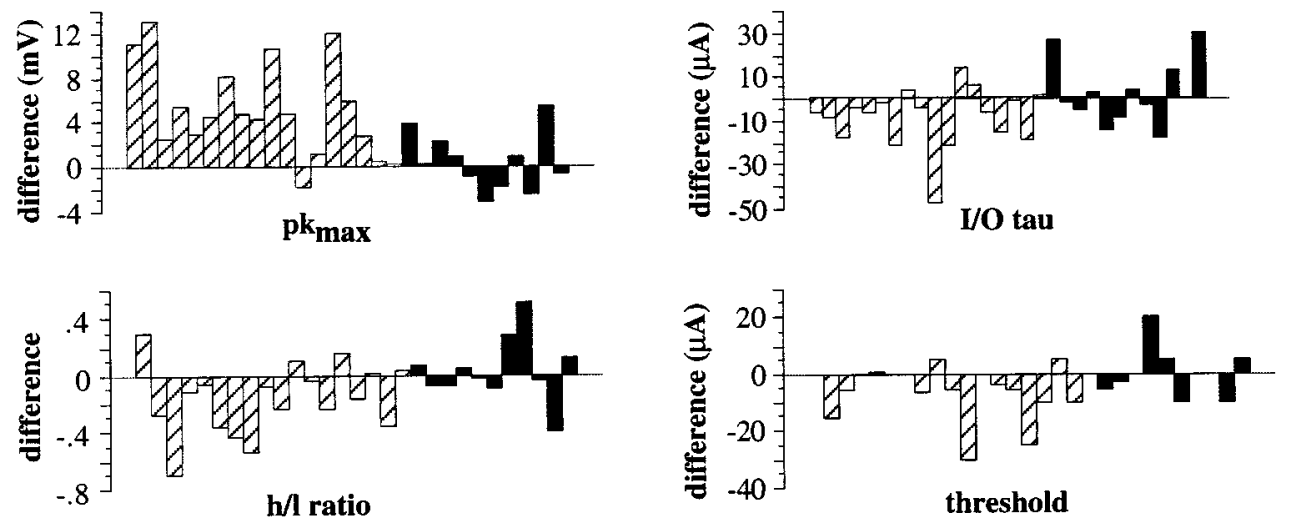

Figure 5. Quantification of the differences between parameters determined for NCB and CB (NCM and CM for control data) stimulation from PSPs

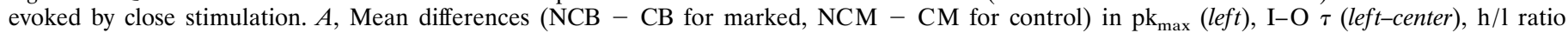
(right-center), and threshold (right). Significance values are from unpaired, Student's $t$ tests performed on each of the difference values from marked versus difference values from control slices. $B$, Individual difference scores (NCB - CB for marked, NCM - CM for control) from each neuron used to calculate the means in $A$.

close stimulation. In control slices, there were no significant differences in any measured parameters between NCM and CM stimulation. However, in marked slices, in which a representational border intervened between $\mathrm{CB}$ stimulation and the neuron, there were significant differences between NCB and CB stimulation for $\mathrm{Pk}_{\max }, \mathrm{I}-\mathrm{O} \tau, \mathrm{h} / \mathrm{l}$ ratio, and threshold (Table 1, Fig. 5). Furthermore, for $\mathrm{pk}_{\max }, \mathrm{I}-\mathrm{O} \tau$ and $\mathrm{h} / \mathrm{l}$ ratio these differences were significantly different from the corresponding $\mathrm{NCM}$ versus $\mathrm{CM}$ differences for control slices (Fig. $5 A$, unpaired $t$ test). The positive $\mathrm{NCB}-\mathrm{CB}$ differences for $\mathrm{pk}_{\max }, \tau$, and threshold indicate that excitation, probably both monosynaptic and polysynaptic, was smaller with $\mathrm{CB}$ than with $\mathrm{NCB}$ stimulation. One alternative possibility, that there was more inhibition with $\mathrm{CB}$ stimulation, was rejected because inhibition, as measured by IPSPs, was also weaker with CB stimulation (Fig. 6).

From the reversal potential data in Figure 4, it is clear that the later components of the PSP are dominated by IPSPs, particularly at higher stimulus intensities. Thus, the $\mathrm{h} / \mathrm{l}$ ratio is a reasonable measure of the amount of inhibition that is activated by higherintensity stimuli. Examination of the data in Table 1 indicates that $t_{1 / 2}$ high, $t_{1 / 2}$ low, and $h / 1$ ratio were all larger with $C B$ stimulation than these parameters were for $\mathrm{NCB}, \mathrm{CM}$, or NCM stimulation. These data suggest that there was less inhibition contributing to PSPs evoked by CB stimulation than there was contributing to those evoked by NCB stimulation. The difference in the amount of inhibition was particularly apparent at higher stimulus intensities in which inhibition of the PSPs was strongest.

\section{Effects on IPSPs}

The suggestion that inhibition might also be weaker with $\mathrm{CB}$ stimulation led us to examine IPSPs directly. Monosynaptic IPSPs were isolated by bathing slices in 10-15 $\mu \mathrm{M}$ DNQX (or CNQX) plus $100 \mu \mathrm{M}$ APV. Bath application of 10-25 $\mu \mathrm{m}$ bicuculline methiodide blocked these IPSPS $(n=6$; Fig. $6 B)$. In four of six neurons, there was a small residual PSP of unknown type, even in the presence of CNQX, APV, and bicuculline (Fig. $6 B$ ). This remnant potential could be similar to the slow excitatory PSP detected in rat layer $\mathrm{V}$ neurons, which has been shown to be a combination of cholinergic and noradrenergic PSPs (Benardo, 1993). Furthermore, $\mathrm{GABA}_{\mathrm{B}}$-mediated PSPs were not observed because of the block of the $\mathrm{K}^{+}$channel activated by the $\mathrm{GABA}_{\mathrm{B}}$ receptor by $\mathrm{Cs}^{+}$and QX-314 in the electrode (Otis et al., 1993). The lack of any $\mathrm{GABA}_{\mathrm{B}}$ response was confirmed in a few cells $(n=4)$ by bath application of the general $\mathrm{GABA}_{\mathrm{B}}$ antagonist, CGP35348 (CIBA, Suffren, NY) (Fig. 6B). Examples of monosynaptic IPSPs evoked by CB (top traces) and NCB (bottom traces) stimulation are shown in Figure $6 \mathrm{~A}$.

These IPSPs were quantified in a similar manner to the compound PSPs: the amplitude at the peak and the $50 \%$ fall time were determined for the IPSP evoked at each stimulus intensity, and the maximal peak amplitude $\left(\mathrm{ipk}_{\max }\right), \mathrm{I}-\mathrm{O} \mathrm{i} \tau$, threshold, and the maximal and mean $\mathrm{t}_{1 / 2}$ values ( $\mathrm{it}_{1 / 2}$ max and $\mathrm{it}_{1 / 2}$ mean) were determined for the neuron. The mean values of these parameters for $\mathrm{CB}$ and $\mathrm{NCB}$ stimulation are presented in Table 2. The mean of the difference scores $(\mathrm{NCB}-\mathrm{CB})$ for these parameters for 
A)

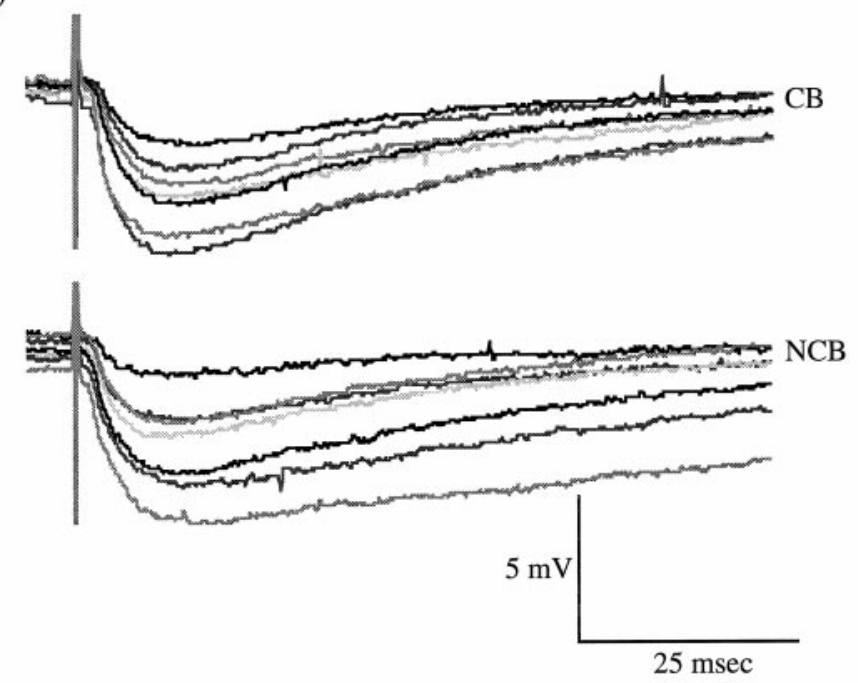

C)
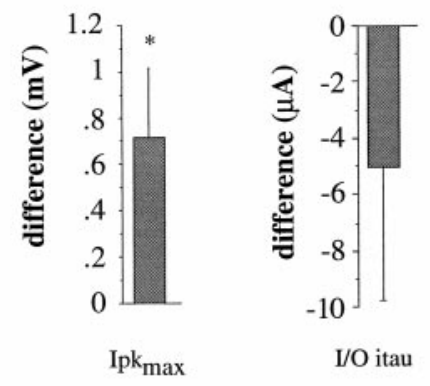

D)

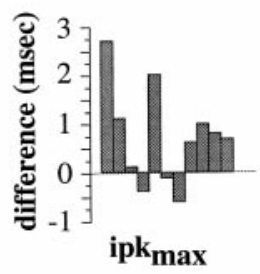

$25 \mathrm{msec}$
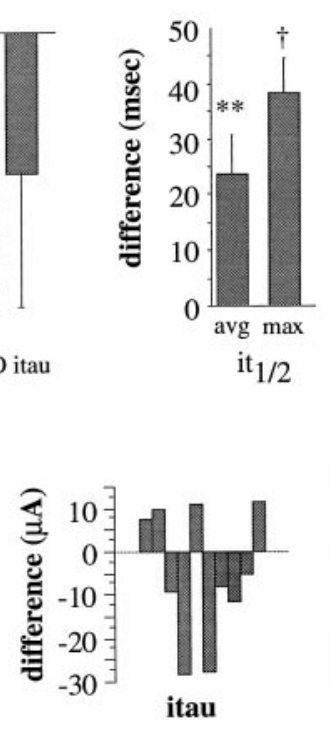

B)
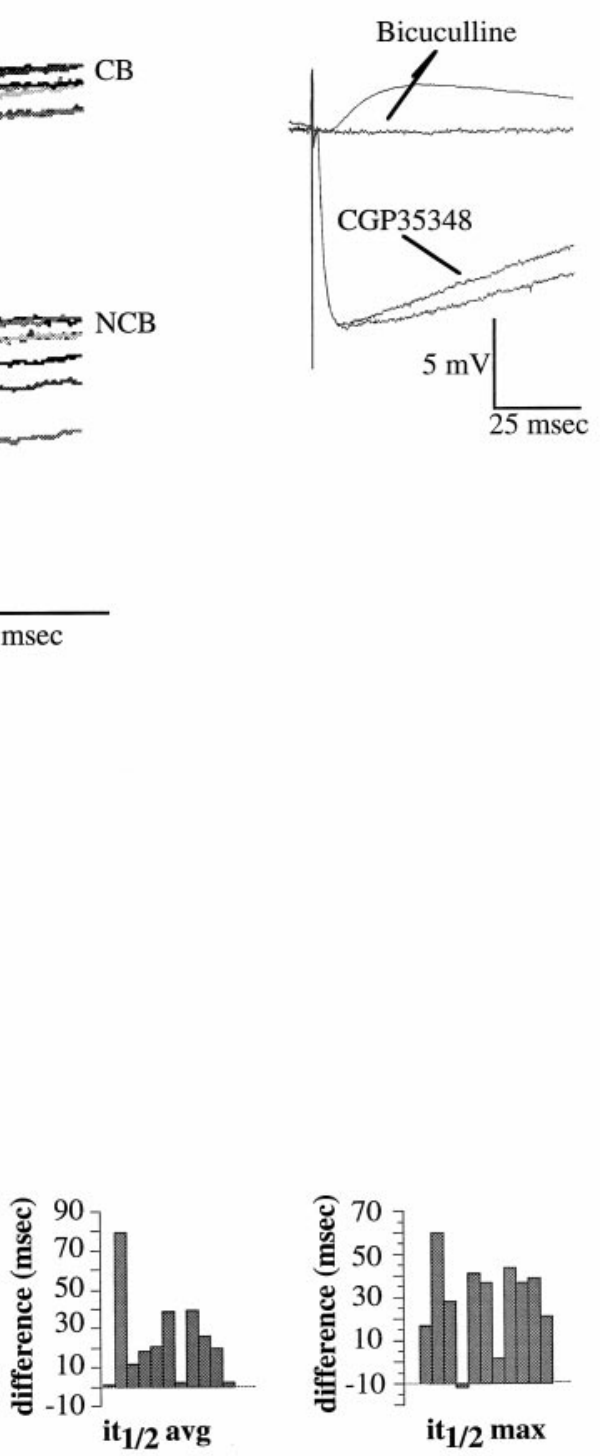

Figure 6. Examples of monosynaptic IPSPs and quantification of differences between NCB and CB stimulation. $A$, Examples of direct IPSPs recorded in the presence of $12 \mu \mathrm{M}$ DNQX and $100 \mu \mathrm{M} \mathrm{APV}$; the membrane potential was adjusted to $-45 \mathrm{mV}$. These IPSPs were recorded from the same neuron as were the PSPs shown in Figure 2. Corresponding shades of gray represent responses from corresponding stimulus intensities as in Figure 3. Top traces, averages of 3-5 IPSPs evoked from minimal to maximal stimulus intensities, CB stimulation. Bottom traces, IPSPs evoked with NCB stimulation in the same cell. $B$, Effects of $50 \mu \mathrm{M}$ CGP35348 (second from bottom trace) and bicuculline (top traces) on IPSPs. Note the residual EPSP in the presence of bicuculline in some cases. Each trace is the average of three potentials, and the membrane potential was adjusted to $-45 \mathrm{mV}$. $C$, Mean differences $(\mathrm{NCB}-\mathrm{CB})$ in $\mathrm{ipk}_{\max }($ left $), \mathrm{I}-\mathrm{O} \mathrm{i} \tau$ (center), it $\mathrm{t}_{1 / 2}$ avg and $\mathrm{it}_{1 / 2} \max (r i g h t)$. Significance values are from paired, Student's $t$ tests performed on each of the parameters from NCB stimulation versus those from $\mathrm{CB}$ stimulation, $n=11$ neurons. ${ }^{*} p<0.05$; ** $p<0.01$. $D$, Individual difference scores from each neuron used to calculate the means in $B$.

each neuron is shown in Figure $6 C$, and the individual differences used to generate these means are shown in Figure 6D. Monosynaptic IPSPs had smaller amplitudes (ipk $\max ; \mathrm{I}-\mathrm{O} \mathrm{i} \tau)$ and durations ( it $_{1 / 2}$ max and it $_{1 / 2}$ avg) with CB stimulation than with NCB stimulation, confirming the relative weakness of inhibition with $\mathrm{CB}$ stimulation that was suggested by the data from the compound PSPs.

\section{PSPs evoked by distant stimulation}

The PSPs discussed so far were evoked with stimuli within 300 $\mu \mathrm{m}$ of the impaled neuron. Even with the cut to isolate layer $2 / 3$, the circuitry activated by such stimuli is complex and could include both orthodromic and antidromic activation of horizontal connections, axons and their recurrent collaterals, isolated thalamocortical arbors, and processes of the impaled neuron. PSPs were therefore evoked with more distant stimulation (between 450 and $800 \mu \mathrm{m}$ ) in which there would be a relatively greater contribution to the PSPs by the activation of layer $2 / 3$ horizontal connections. Examples of PSPs evoked by distant stimulation from CB (top traces) and NCB (bottom traces) sites are presented in Figure $7 A$; the PSPs shown were evoked using minimal to maximal stimulus intensities. The same parameters 


\section{Table 2. IPSP parameters}

\begin{tabular}{lcc} 
& CB stimulation & NCB stimulation \\
\hline Latency $(\mathrm{msec})$ & $2.82 \pm 0.33$ & $2.65 \pm 0.3$ \\
$\mathrm{Ipk}_{\max }(\mathrm{mV})$ & $4.57 \pm 0.33^{a}$ & $5.29 \pm 0.44$ \\
$\mathrm{I}-\mathrm{O} \tau(\mu \mathrm{A})$ & $60.0 \pm 4.3$ & $55.0 \pm 4.5$ \\
$\mathrm{It}_{1 / 2}$ avg $(\mathrm{msec})$ & $81.1 \pm 10.6^{b}$ & $104.6 \pm 13.7$ \\
$\mathrm{It}_{1 / 2} \max (\mathrm{msec})$ & $121.3 \pm 16.0^{c}$ & $159.8 \pm 17.3$ \\
Threshold $(\mu \mathrm{A})$ & $25.3 \pm 6.7$ & $21.6 \pm 7.9$
\end{tabular}

$\overline{\text { Parameters from CB and NCB stimulation were compared using paired Student's } t}$ tests.

${ }^{a}$ Significantly different from NCB stimulation, $p<0.05$.

${ }^{b}$ Significantly different from NCB stimulation, $p<0.01$.

${ }^{c}$ Significantly different from NCB stimulation, $p<0.0001$.

were measured for these PSPs as were measured for PSPs evoked by close stimulation, and are summarized in Table 1. PSPs evoked by distant stimulation were qualitatively similar to those evoked by close stimulation. Their peak amplitudes increased with increasing stimulus intensity until a plateau was reached, reflecting increasing activation of excitatory inputs, and were well fit by a single exponential. Their fall times tended to be shorter at higher stimulus intensities. However, late hyperpolarizations were less frequently observed ( 4 of 11 cells). This observation indicates that inhibition played a weaker role in the late components of these PSPs, which were more strongly dominated by excitation. This observation is unsurprising, because the range of monosynaptic inhibitory connections in rat S1 slices has been determined to be $\sim 400 \mu \mathrm{m}$ (Salin and Prince, 1996), which leaves only polysynaptic inhibition to suppress excitation in the distant stimulation case. Furthermore, PSPs evoked by distant stimulation had significantly smaller amplitudes $\left(\mathrm{Pk}_{\max }\right.$ and $\mathrm{I}-\mathrm{O} \tau$; Table 1$)$, and larger fall times and thresholds $\left(\mathrm{t}_{1 / 2}\right.$ low, $\mathrm{t}_{1 / 2}$ high, and threshold; Table 1$)$ than those evoked by close stimulation.

Differences in these parameters between NCB and CB stimulation are summarized in Figure $7, B$ and $C$ : mean difference scores $(\mathrm{NCB}-\mathrm{CB})$ are shown in Figure $7 B$ and individual difference scores are shown in Figure $7 C$. The mean difference scores from PSPs evoked by distant stimulation (Fig. 7B) were qualitatively similar to those from close stimulation (Fig. 5) for $\mathrm{Pk}_{\max }$, I-O $\tau$, and threshold, indicating that excitation was smaller with $\mathrm{CB}$ stimulation than with NCB stimulation. For the distant stimulation case, the mean $\mathrm{h} / \mathrm{l}$ ratio was smaller for $\mathrm{CB}$ stimulation than for NCB stimulation, although the difference was not significant. This finding was opposite to that observed for close stimulation, in which the $\mathrm{h} / \mathrm{l}$ ratio was smaller for $\mathrm{NCB}$ stimulation. This difference in $\mathrm{h} / \mathrm{l}$ ratio between distant and close stimulation was expected, as inhibition in general was weaker with distant stimulation, leading to generally larger $t_{1 / 2}$ values (Table 1). The positive $\mathrm{NCB}-\mathrm{CB}$ difference in $\mathrm{h} / \mathrm{l}$ ratio therefore probably reflects a smaller amount of late (presumably polysynaptic) excitation with CB stimulation.

Thus, the data from PSPs evoked by both close and distant stimulation support the conclusion that excitation is significantly weaker when evoked by $\mathrm{CB}$ stimulation as compared with NCB stimulation. The conclusion that inhibition is also smaller with $\mathrm{CB}$ stimulation is strongly supported by the data from short stimulation, but cannot be effectively assayed for distant stimulation caused by the relatively small contribution of inhibition to these PSPs.

\section{DISCUSSION}

In these studies, it has been demonstrated that a "representational discontinuity" or "border" between two cortical representations in rat S1 marks a relative barrier for effective excitatory and inhibitory transmission onto supragranular neurons close to the border. This reduction in effectiveness only depended on the synaptic and local circuit properties of neurons in supragranular layers, because the reduction was observed in an in vitro preparation in which the supragranular layers were physically isolated from deeper cortical layers. These data indicate that the reduction of information transfer across representational borders does not solely result from feedforward intracortical inhibition preventing the activation of neurons across the border. On the contrary, inhibitory projections across the border are actually weaker than those that do not cross.

\section{Mapping the forepaw-lower jaw border}

The approximate location and orientation of the forepaw and lower jaw regions observed in this study correspond to those previously observed using more detailed mapping procedures (Chapin and Lin, 1984; Waters et al., 1995). The border between forepaw and lower jaw representations was generally quite distinct. However, we also (at least one site in $\sim 40 \%$ of maps) observed penetrations near the border that responded to both forepaw and lower jaw stimulation, usually unequally. These dual-response penetrations often seemed to be associated with lighter states of anesthesia, but were also detected in animals that appeared to be more deeply anesthetized. Such penetrations probably reflected the use of multiunit recording, relatively highintensity skin stimulation, and location of these penetrations in perigranular regions of $\mathrm{S} 1$ in which receptive field sizes tend to be large (Fig. $1 B$ ), and neuronal responses tend to be higher threshold (Chapin and Lin, 1984). The maps that were derived were stable over the course of the mapping and marking and showed no change after iontophoretic deposition of dye. There was no evidence of any toxic effect of the dye or of the iontophoresis procedure on the tissue at or near the marked sites. Thus, the tissue obtained for in vitro analysis was healthy, and appropriate controls demonstrated the observed effects of the border were not an artifact of damage to or experimental alteration of the superficial cortex.

\section{PSPs in marked slices}

The PSPs evoked in this preparation resembled those evoked by stimulation of layer $2 / 3$ in undercut slices from cat visual cortex (Hirsch and Gilbert, 1991), or by activation of horizontal pathways in rat motor cortex (Hess et al., 1996). These connections arise from layer $2 / 3$ pyramidal neurons that form excitatory synapses locally and at longer distances (Chapin et al., 1987; Hoeflinger et al., 1995) and from nonpyramidal neurons that form inhibitory synapses, primarily locally (Salin and Prince, 1996). For both excitation and inhibition, additional polysynaptic events can be relayed over much longer distances at longer delays (Sutor and Hablitz, 1989a,b). The PSPs shown in Figures 3, 6, and 7 clearly exhibit these characteristics. Judged by the reversal potential of PSCs (Fig. 4), the compound PSPs recorded were typically combinations of EPSPs and IPSPs. At maximal stimulation, the peak of the PSP appeared to be dominated by EPSPs, because the reversal potential was $\sim 0 \mathrm{mV}$ (Fig. $4 A$ ), whereas the later components of the PSPs were dominated by inhibition (Fig. $4 B$ ). The amount of inhibition, however, decreased dramatically with 
A)

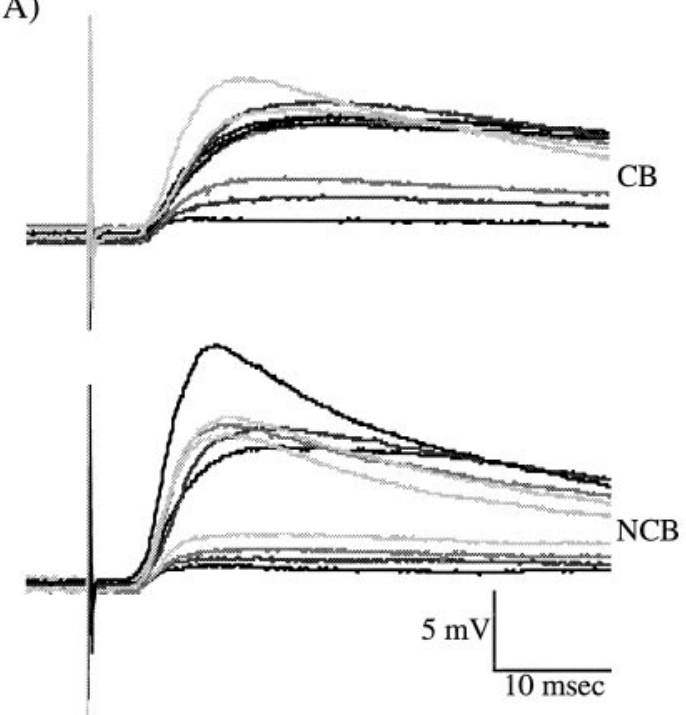

B)

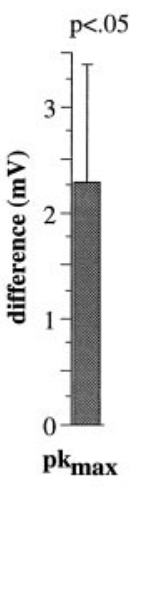

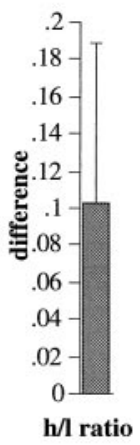

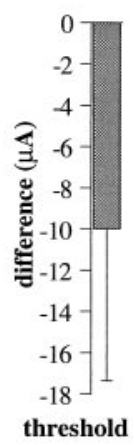

C)
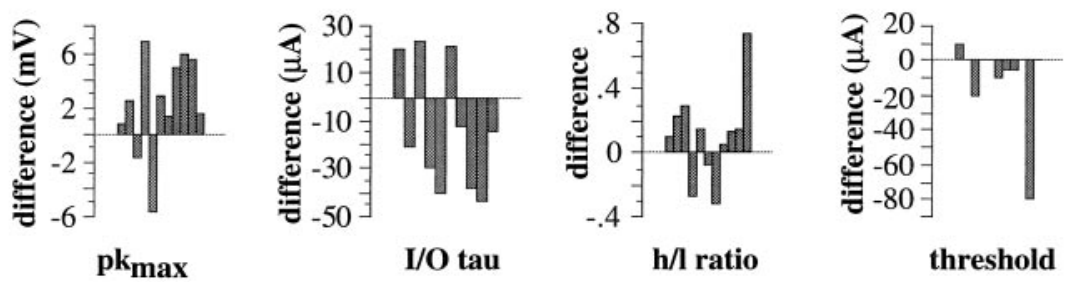

Figure 7. Examples of PSPs evoked by distant $(\sim 700 \mu \mathrm{m}$ in this example) stimulation and quantification of differences between NCB and CB stimulation. A, Examples of PSPs evoked by distant stimulation for CB (top traces) and NCB (bottom traces) stimulation. Each trace is the average of 3-5 individual responses; corresponding shades of gray represent responses from corresponding stimulus intensities as in Figure 3. The membrane potential of the neuron was adjusted to $-50 \mathrm{mV} . B$, Mean differences $(\mathrm{NCB}-\mathrm{CB})$ in $\mathrm{pk}_{\max }($ left $), \mathrm{I}-\mathrm{O} \tau($ left-center), h/l ratio (right-center) and threshold (right). Significance values are from paired, Student's $t$ tests performed on each of the parameters from NCB stimulation versus those from CB stimulation, $n=11$ neurons. $C$, Individual difference scores $(\mathrm{NCB}-\mathrm{CB}$ ) from each neuron used to calculate the means in $B$.

greater stimulation distance (Fig. 7), as previously demonstrated (Salin and Prince, 1997).

Is this study, we believe that all the PSPs observed primarily reflect activation of intrinsic horizontal connections. However, the circuitry of layer $2 / 3$ is complex; thus, the relatively large electrical stimuli used in this study would be expected to activate many different circuitry elements, including horizontal connections, axon collaterals, thalamocortical terminals, and possibly the processes of the impaled neuron. The last two possibilities would be most likely in the close stimulation category because of the close proximity of the stimulating and recording sites. However, blocking synaptic transmission with $0 \mathrm{Ca}^{2+}$ and high $\mathrm{Mg}^{2+}$ buffer revealed that there was negligible direct activation of neurons, even with this close stimulation. Large contributions by activation of thalamocortical terminals would be unlikely, because only small, isolated remnants of these terminals would remain after undercutting layer $2 / 3$. Furthermore, minor direct activation of either the neuron, itself, or of thalamocortical terminal remnants did not appear to bias our results, because similar differences between PSPs evoked by NCB and CB stimulation were observed with distant stimulation (Fig. 7) in which direct activation would be minimal.

Activation of horizontal fibers of passage and collaterals from layer $2 / 3$ neurons undoubtedly occurred, causing antidromic activation of more distant supragranular neurons. Thus, both $\mathrm{CB}$ and NCB stimulation could have activated neurons on both sides of the border, reducing the specificity of stimulation. Nevertheless, differences in both EPSPs and IPSPs with CB versus NCB stimulation were routinely observed, even at maximal stimulus intensities. Therefore, this nonspecific antidromic activation appears to have made only a minor contribution to the PSPs observed.

All of the current-voltage relationships in Figure 4 are approximately linear; the presence of QX-314 in the electrode is known to block a sodium current that is responsible for most of the nonlinearity in horizontally evoked EPSPs (Hirsch and Gilbert, 1991) and in EPSPs evoked by white matter stimulation (Sutor and Hablitz, 1989a,b), although there is some contribution of NMDA receptor activation to the nonlinearities observed in those studies.

\section{Anatomical and physiological correlates of the border}

The border between forepaw and lower jaw representations was selected for these experiments because there is little overlap of these two representations (Chapin and Lin, 1984). In the rat, the region between the forepaw and lower jaw granular (layer 4) zones consists of an $\sim 100-500 \mu \mathrm{m}$ wide region of relatively agranular cortex, referred to as a perigranular or intercalated zone (Chapin and Lin, 1984; Fabri and Burton, 1991) (Fig. 1B). The granular regions are thought to reflect the termination zones 
of thalamocortical afferents (Killackey and Belford, 1979; Dawson and Killackey, 1987) and have been hypothesized to be analogous to primate area $3 \mathrm{~b}$. Primarily on the basis of their physiological response properties, the perigranular and intercalated zones have been hypothesized to be analogous to primate area 1 and 2, respectively (Chapin and Lin, 1984; Fabri and Burton, 1991). There is a relatively close correspondence between the cellular organization of the forepaw representation (i.e., the forepaw barrel subfield) and the physiological map of the forepaw in the normal rat (Waters et al., 1995). Thus, there is an observable morphological border between the forepaw and lower jaw representations. However, anatomical substrates cannot account for the precision of the representational border because the transition between forepaw and lower jaw representation assayed physiologically occurs over an $\sim 50-75 \mu \mathrm{m}$ interval in the pentobarbital-anesthetized rat, which is much more abrupt than the separation between the anatomically distinct zones of the forepaw and lower jaw (separated by $\sim 100-500 \mu \mathrm{m}$ ). Thus, there is a clear discrepancy between the anatomical and physiological maps.

There are several other anatomical substrates that do not precisely reflect functionally defined representational borders. (1) The terminals of thalamocortical axons have been shown to overlap extensively in adult rat (Jensen and Killackey, 1987a) and primate (Garraghty et al., 1989; Garraghty and Sur, 1990; Rausell and Jones, 1995). In the cat (Landry and Deschenes, 1981; Snow et al., 1988) and primate (Rausell and Jones, 1995) this overlap can span representational borders. (2) The basilar dendrites of supragranular neurons in perigranular zones of rat S1 can extend up to $500 \mu \mathrm{m}$ into adjacent granular zones (Chapin et al., 1987). (3) Intracortical horizontal projections extend for long distances throughout the cortex. These projections extend locally for $\sim 500-600 \mu \mathrm{m}$ in all regions and for longer distances (millimeters) particularly within and between perigranular and dysgranular regions. However, the relative density of these horizontal connections is not uniform: injections of anterograde and retrograde tracers into rat S1 typically yield a "halo" of short range (approximately $<500 \mu \mathrm{m}$ ) horizontal projections which have a relatively even radial distribution. At longer distances, the density of horizontal connections within a cytoarchitectonic region is greater than the density between such regions (Chapin et al., 1987; Fabri and Burton, 1991; Hoeflinger et al., 1995). Overall, it is not surprising that subthreshold EPSPs can be detected for inputs that cross representational boundaries (Zarzecki et al., 1993; Istvan and Zarzecki, 1994; Li and Waters, 1996).

Corticocortical projections of parietal regions of neocortex terminate in discrete columns or bands in rats (Isseroff et al., 1984) and primates (Jones et al., 1975). Such columnar organization has been suggested to be a distinctive feature of cortical functional and anatomical organization (Mountcastle, 1997). Surprisingly, the widths of these columns are approximately equal across species $(\sim 400-750 \mu \mathrm{m})$. The precise relationship of these columns with the physiological borders between representations is not certain, although previous studies in rat suggest that perigranular or intercalated regions in S1 may correspond to the width of a column (Chapin and Lin, 1987), implying that our borders would generally be near the center of a column. Therefore, our close stimulation category would most likely be within the same column as the impaled neuron, and would thus strongly activate intrinsic intracolumnar connections, as well as some longer-range intercolumnar connections. Our distant stimulation category suggests that the effects of this representational border also apply to intercolumnar horizontal connections, as well.

The relative weakness of excitation across representational borders could be because: (1) cross-border excitation is too weak to cause neurons to reach firing threshold; (2) cross-border inhibition prevents neurons from reaching threshold; or (3) both of these processes occur. Our data support the first of these possible explanations, that cross-border excitation is weaker than excitation within a representation. The data in Figures 3, 5 and 7, and in Table 1 clearly show that the $\mathrm{Pk}_{\max }, \mathrm{I}-\mathrm{O} \tau$, and threshold are smaller for CB stimulation. Because these parameters primarily reflect activation of EPSPs (Fig. 4), net cross-border excitation is weaker than same-side excitation. No evidence was found for stronger inhibition with $\mathrm{CB}$ stimulation. In fact, monosynaptic IPSPs were smaller in amplitude and shorter in duration (Fig. 6, Table 2) for CB stimulation. Furthermore, with close stimulation in which a significant amount of inhibition was activated, the $h / 1$ ratio was larger with $\mathrm{CB}$ stimulation, reflecting a smaller contribution of later IPSPs to the PSPs evoked by stronger stimuli. Our data only apply to corticocortical connections, because thalamocortical projections were severed by the cut in layer 4 (Fig. 2A). Thus, it is possible that feedforward inhibition driven by thalamocortical projections could drive cross-border inhibition and further contribute to the suppression of EPSPs in the intact animal.

Our data are consistent with and do not differentiate between there either being a smaller number of excitatory and inhibitory projections that cross the border, or that the synapses that these cross-border projections make are weaker than those made by noncross-border projections, or both. Because the density of horizontal projections tends to be greater within as opposed to between representations, the first alternative would seem likely. However, over the distances between stimulating and recording used in these studies for close stimulation $(<300 \mu \mathrm{m})$, horizontal projections are quite evenly distributed (Chapin et al., 1987; Fabri and Burton, 1991; Hoeflinger et al., 1995). Further studies are necessary to resolve these issues.

This in vivo and in vitro preparation provides a novel system in which to study the basic cellular and synaptic events that underlie the establishment of dynamic representational borders and their plasticity. Clear correlates of a representational border can be detected at the level of single cortical neurons by comparing the responses of intracortical connections that must cross a representational border to those that do not. By examining these cellular properties in relation to a representational border that has been reorganized by some peripheral manipulation, we hope to further probe the basic mechanisms that are responsible for representational plasticity of the cortex.

\section{REFERENCES}

Armstrong-James M, Diamond ME, Ebner FF (1994) An innocuous bias in whisker use in adult rats modifies receptive fields of barrel cortex neurons. J Neurosci 14:6978-6991.

Benardo LS (1993) Characterization of cholinergic and noradrenergic slow excitatory postsynaptic potentials from rat cerebral cortical neurons. Neuroscience 53:11-22.

Blanton MG, LoTurco JJ, Kriegstein AR (1989) Whole cell recordings from neurons in slices of reptilian and mammalian cortex. J Neurosci Methods 30:203-210.

Buonomano DV, Merzenich MM (1998) Cortical plasticity: from synapses to maps. Annu Rev Neurosci, in press.

Byrne JA, Calford MB (1991) Short-term expansion of receptive fields in rat primary somatosensory cortex after hindpaw digit denervation. Brain Res 565:218-224.

Calford M, Tweedale R (1988) Immediate and chronic changes in re- 
sponses of somatosensory cortex in adult flying-fox after digit amputation. Nature 332:449-449.

Calford MB, Tweedale R (1991a) Acute changes in cutaneous receptive fields in primary somatosensory cortex after digit denervation in adult flying fox. J Neurophysiol 65:178-187.

Calford MB, Tweedale R (1991b) Immediate expansion of receptive fields of neurons in area $3 \mathrm{~b}$ of macaque monkeys after digit denervation. Somatosens Mot Res 8:249-260.

Catalano SM, Robertson RT, Killackey HP (1996) Individual axon morphology and thalamocortical topography in developing rat somatosensory cortex. J Comp Neurol 367:36-53.

Chapin J, Lin C-S (1984) Mapping the body representation in the SI cortex of anesthetized and awake rats. J Comp Neurol 229:199-213.

Chapin JK, Sadeq M, Guise JL (1987) Corticocortical connections within the primary somatosensory cortex of the rat. J Comp Neurol 263:326-346.

Chino Y, Kaas J, Smith E, Langston A, Cheng H (1992) Rapid reorganization of cortical maps in adult cats following restricted deafferentation in retina. Vision Res 32:789-796.

Crair MC, Malenka RC (1995) A critical period for long-term potentiation at thalamocortical synapses. Nature 375:325-328.

Darian-Smith C, Gilbert C (1994) Axonal sprouting accompanies functional reorganization in adult cat striate cortex. Nature 368:737-740.

Darian-Smith C, Gilbert CD (1995) Topographic reorganization in the striate cortex of the adult cat and monkey is cortically mediated. J Neurosci 15:1631-1647.

Das A, Gilbert CD (1995) Long-range horizontal connections and their role in cortical reorganization revealed by optical recording of cat primary visual cortex. Nature 375:780-784.

Dawson DR, Killackey HP (1987) The organization and mutability of the forepaw and hindpaw representations in the somatosensory cortex of the neonatal rat. J Comp Neurol 256:246-256.

Donoghue J, Suner S, Sanes J (1990) Dynamic organization of primary motor cortex output to target muscles in adult rats II. Rapid reorganization following motor nerve lesions. Exp Brain Res 79:492-503.

Fabri M, Burton H (1991) Ipsilateral cortical connections of primary somatic sensory cortex in rats. J Comp Neurol 311:405-424.

Garraghty PE, Sur M (1990) Morphology of single intracellularly stained axons terminating in area $3 \mathrm{~b}$ of macaque monkeys. J Comp Neurol 294:583-593.

Garraghty PE, Pons TP, Sur M, Kaas JH (1989) The arbors of axons terminating in middle cortical layers of somatosensory area $3 \mathrm{~b}$ in owl monkeys. Somatosens Mot Res 6:401-411.

Hess G, Donoghue JP (1994) Long-term potentiation of horizontal connections provides a mechanism to reorganize cortical motor maps. J Neurophysiol 71:2543-2547.

Hess G, Aizenman CD, Donoghue JP (1996) Conditions for the induction of long-term potentiation in layer II/III horizontal connections of the rat motor cortex. J Neurophysiol 75:1765-1778.

Hickmott PW, Merzenich MM (1996) Single-cell correlates of representational boundaries in rodent S1 cortex. Soc Neurosci Abstr 22:1133.

Hirsch JA, Gilbert CD (1991) Synaptic physiology of horizontal connections in the cat's visual cortex. J Neurosci 11:1800-1809.

Hirsch JA, Gilbert CD (1993) Long-term changes in synaptic strength along specific intrinsic pathways in the cat visual cortex. J Physiol (Lond) 461:247-262.

Hoeflinger BF, Bennett-Clarke CA, Chiaia NL, Killackey HP, Rhoades RW (1995) Patterning of local intracortical projections within the vibrissae representation of rat primary somatosensory cortex. J Comp Neurol 354:551-563.

Huntley GW (1997) Correlation between patterns of horizontal connectivity and the extend of short-term representational plasticity in rat motor cortex. Cereb Cortex 7:143-156.

Huntley GW, Jones EG (1991) Relationship of intrinsic connections to forelimb movement representations in monkey motor cortex: a correlative anatomic and physiological study. J Neurophysiol 66:390-413.

Isseroff A, Schwartz ML, Dekker JJ, Goldman-Rakic PS (1984) Columnar organization of callosal and associational projections from rat frontal cortex. Brain Res 293:213-223.

Istvan PJ, Zarzecki P (1994) Intrinsic discharge patterns and somatosensory inputs for neurons in raccoon primary somatosensory cortex. J Neurophysiol 72:2827-2839.

Jensen KF, Killackey HP (1987a) Terminal arbors of axons projecting to the somatosensory cortex of the adult rat. I. The normal morphology of specific thalamocortical afferents. J Neurosci 7:3529-3543.
Jensen KF, Killackey HP (1987b) Terminal arbors of axons projecting to the somatosensory cortex of the adult rat. II. The altered morphology of thalamocortical afferents following neonatal infraorbital nerve cut. J Neurosci 7:3544-3553.

Jones EG, Burton H, Porter R (1975) Commissural and corticocortical "columns" in the somatic sensory cortex of primates. Science 190:572-574.

Kaas JH (1983) What, if anything, is SI? Organization of first somatosensory area of cortex. Physiol Rev 63:206-231.

Kaas JH (1991) Plasticity of Sensory and Motor Maps in Adult Mammals. Annu Rev Neurosci 14:137-166.

Killackey HP, Belford GR (1979) The formation of afferent patterns in the somatosensory cortex of the neonatal rat. J Comp Neurol 183:285-303.

Kirkwood A, Bear M (1994) Hebbian synapses in visual cortex. J Neurosci 14:1634-1645.

Kirkwood A, Dudek SM, Gold JT, Aizenman CD, Bear M (1993) Common forms of synaptic plasticity in the hippocampus and neocortex in vitro. Science 260:1518-1521.

Landry P, Deschenes M (1981) Intracortical arborizations and receptive fields of identified ventrobasal thalamocortical afferents to the primary somatic sensory cortex in the cat. J Comp Neurol 199:345-371.

Lee SM, Ebner FF (1992) Induction of high frequency activity in the somatosensory thalamus of rats in vivo results in long-term potentiation of responses in SI cortex. Exp Brain Res 90:253-261.

Lee SM, Weisskopf MG, Ebner FF (1991) Horizontal long-term potentiation of responses in rat somatosensory cortex. Brain Res 544:303-310.

Li CX, Waters RS (1996) In vivo intracellular recording and labeling of neurons in the forepaw barrel subfield (FBS) of rat somatosensory cortex: possible physiological and morphological substrates for reorganization. NeuroReport 7:2261-2272.

McCandlish CA, Cheng XL, Waters RS, Howard EM (1996) Digit removal leads to discrepancies between the structural and functional organization of the forepaw barrel subfield in layer IV of rat primary somatosensory cortex. Exp Brian Res 108:417-426.

Merzenich MM, Jenkins WM (1993) Reorganization of cortical representations of the hand following alterations of skin inputs induced by nerve injury, skin island transfers, and experience. $\mathrm{J}$ Hand Ther 6:89-104.

Merzenich MM, Kaas JH, Sur M, Lin CS (1978) Double representation of the body surface within cytoarchitectonic areas $3 b$ and 1 in "SI" in the owl monkey (aotus trivirgatus). J Comp Neurol 181:41-73.

Merzenich M, Recanzone G, Jenkins W, Grajski K (1990) Adaptive mechanisms in cortical networks underlying cortical contributions to learning and nondeclarative memory. Cold Spring Harb Symp Quant Biol 55:873-887.

Mountcastle VB (1997) The columnar organization of the neocortex. Brain 120:701-722.

Nicolelis MA, Lin RC, Woodward DJ, Chapin JK (1993) Induction of immediate spatiotemporal changes in thalamic networks by peripheral block of ascending cutaneous information. Nature 361:533-536.

Nudo R, Jenkins W, Merzenich M (1990) Repetitive microstimulation alters the cortical representation of movements in adult rats. Somatosens Mot Res 7:463-483.

Otis TS, De Koninck Y, Mody I (1993) Characterization of synaptically elicited $\mathrm{GABA}_{\mathrm{B}}$ responses using patch-clamp recordings in rat hippocampal slices. J Physiol (Lond) 463:391-407.

Pettet MW, Gilbert CD (1992) Dynamic changes in receptive-field size in cat primary visual cortex. Proc Natl Acad Sci USA 89:8366-8370.

Rausell E, Jones EG (1995) Extent of intracortical arborization of thalamocortical axons as a determinant of representational plasticity in monkey somatic sensory cortex. J Neurosci 15:4270-4288.

Recanzone G, Merzenich M, Dinse H (1992a) Expansion of the cortical representation of a specific skin field in primary somatosensory cortex by intracortical microstimulation. Cereb Cortex 2:181-196.

Recanzone G, Merzenich M, Jenkins W, Grajski K, Dinse H (1992b) Topographic reorganization of the hand representation in cortical area $3 \mathrm{~b}$ of owl monkeys trained in a frequency-discrimination task. J Neurophysiol 67:1031-1056.

Salin PA, Prince DA (1996) Electrophysiological mapping of $\mathrm{GABA}_{\mathrm{A}}$ receptor-mediated inhibition in adult rat somatosensory cortex. J Neurophysiol 75:1589-1600.

Snow PJ, Nudo RJ, Rivers W, Jenkins WM, Merzenich MM (1988) 
Somatotopically inappropriate projections from thalamocortical neurons to the SI cortex of the cat demonstrated by the use of intracortical microstimulation. Somatosens Res 5:349-372.

Sutor B, Hablitz JJ (1989a) EPSPs in rat neocortical neurons in vitro. I. Electrophysiological evidence for two distinct EPSPs. J Neurophysiol 61:607-620.

Sutor B, Hablitz JJ (1989b) EPSPs in rat neocortical neurons in vitro II: involvement of $N$-methyl-D-aspartate receptors in the generation of EPSPs. J Neurophysiol 61:621-634.

Turnbull B, Rasmussen D (1990) Acute effects of total or partial digit denervation on raccoon somatosensory cortex. Somatosens Mot Res $7: 365-389$.

Wang X, Merzenich MM, Sameshima K, Jenkins WM (1995) Remodelling of hand representation in adult cortex determined by timing of tactile stimulation. Nature 378:71-75.

Waters RS, Li CX, McCandlish CA (1995) Relationship between the organization of the forepaw barrel subfield and the representation of the forepaw in layer IV of rat somatosensory cortex. Exp Brain Res 103:183-197.

Weinberger NM (1995) Dynamic regulation of receptive fields and maps in the adult sensory cortex. Annu Rev Neurosci 18:129-158.

Weiss DS, Keller A (1994) Specific patterns of intrinsic connections between representation zones in the rat motor cortex. Cereb Cortex 4:205-214.

Wong-Riley MT, Welt C (1980) Histochemical changes in cytochrome oxidase of cortical barrels after vibrissal removal in neonatal and adult mice. Proc Natl Acad Sci USA 77:2333-2337.

Xerri C, Stern J, Merzenich M (1994) Alterations of the cortical representation of the rat ventrum induced by nursing behavior. J Neurosci 14:1710-1721.

Zarzecki P, Witte S, Smits E, Gordon D, Kirchberger P, Rasmusson D (1993) Synaptic mechanisms of cortical representational plasticity: somatosensory and corticocortical EPSPs in reorganized raccoon SI cortex. J Neurophysiol 69:1422-1432. 